Article

\title{
Synthesis of Amino Core Compounds of Galactosyl Phytosyl Ceramide Analogs for Developing iNKT-Cell Inducers
}

\author{
Yin-Cheng Huang ${ }^{1}$, Li-Wu Chiang ${ }^{2}$, Kai-Shiang Chang ${ }^{2}$, Wen-Chin Su ${ }^{2}$, Yi-Hsian Lin ${ }^{2}$, \\ Kee-Ching Jeng ${ }^{3}$, Kun-I Lin ${ }^{2,4}$, Kuo-Yen Liao ${ }^{2}$, Ho-Lein Huang ${ }^{2}$ and Chung-Shan Yu ${ }^{2,5, *}$ \\ 1 Department of Neurosurgery, Chang Gung Memorial Hospital and Department of Medicine, \\ Chang Gung University, Taoyuan 33305, Taiwan \\ 2 Department of Biomedical Engineering and Environmental Sciences, \\ National Tsing-Hua University, No. 101 sec.2, Guang-Fu Rd., Hsinchu 30043, Taiwan \\ 3 Department of Medical Research, Taichung Veterans General Hospital, Taichung 40705, Taiwan \\ 4 Department of Obstetrics and Gynecology, Chang Bing Show Chwan Memorial Hospital, \\ Lukang Zhen, Changhua 50544, Taiwan \\ 5 Institute of Nuclear Engineering and Science, National Tsing-Hua University, Hsinchu 30043, \\ Taiwan
}

* Author to whom correspondence should be addressed; E-Mail: csyu@mx.nthu.edu.tw; Tel.: +886-3-571-5131 ext. 35582; Fax: +886-3-571-8649.

Received: 20 January 2012; in revised form: 1 March 2012 / Accepted: 6 March 2012 /

Published: 12 March 2012

\begin{abstract}
Aminophytosphingosine and 6-aminogalactosyl phytosphingosine were prepared in $61 \%$ and $40 \%$ yield libraries with 44 carboxylic acids showed that a 4-butylbenzoic acid-derived product exe, respectively. Glycosylation using benzoylprotected lipid resulted in better $\alpha$-selectivity for ceramide analogs, but the yield was less than that obtained with benzyl moieties. Screening the amide rted less cytotoxicity. These analogs were purified for validation of immunological potencies and the $\alpha$-GalCer analog but not the sphingosine analog stimulated human iNKT cell population.
\end{abstract}

Keywords: phytosphingosine; library; cancer; immune; glycosylation 


\section{Introduction}

$\alpha$-Galactosyl ceramide ( $\alpha$-GalCer) [1,2], also called KRN7000, has attracted great attention due to its antitumor effects [3-5]. The bioactivity was initiated through the initial binding of $\alpha$-GalCer to CD1d receptor expressed on antigen presenting cells [6,7], followed by presenting to invariant natural killer T (iNKT) cells $[8,9]$. This signifies the release of several cytokines such as IFN $\gamma$ and IL-4 which are categorized as belonging to the TH1 and TH2 pathways, respectively [10,11]. Whereas both types of cytokine could be elicited through $\alpha$-GalCer, the recent focus has centered on the skewing effect of the TH1/TH2 ratio to direct toward a possible medical indication [12,13]. For example, preferential TH1 signaling is related to cancer therapy, whereas TH2 is associated with antimicrobial activity [14]. However, human clinical trials of $\alpha$-GalCer [15] encountered reduced levels of iNKT cell populations similar to a recent animal study [16]. This might be partially due to the deglycosylated ceramide which mediated the subsequent apoptosis/necrosis cascade.

Numerous approaches to structural modification of the sugar head [7,12,17-20] and truncation of the sphingosine backbone [19,21] or acyl chain [22,23] as well as incorporation of unsaturation in the acyl chain [24] have generated some bioactive leads. For example, some of the truncated compounds are active in the TH2-biased pathway [19,21,25], whereas only rarer cases lead towards the TH1-biased pathway $[24,26]$. $\alpha$-GalCer analogs with $\mathrm{C}$-modified glycosidic linkages have been shown to possess this feature, probably due to their inertness to metabolic cleavage of the glycosidic bond [24]. Hence, an amide bond with reasonable inertness might provide an alternative to the glycosidic bond. Consequently an amide library derived from 1-amino phytosphingosine analogs $\mathbf{1}$ with variation of acyl groups was prepared and screened to find which structural features had moderate cytotoxicities. With such a structural type in hand, compounds that incorporated this acyl group into $\alpha$-galactosyl sphingosine 2 at the sugar 6-amino and (or) the 2-amino group of the sphingoid base were evaluated for immunostimulating potency. The concept for the design of our synthesis and screening is outlined in Scheme 1B.

The structure activity relationship (SAR) of $\alpha$-GalCer complexed with the CD1d receptor shows that the 6-OH group of the galactose portion is not required for hydrogen bonding [27,28], thus providing a possibility for structural modification [26,29-31]. Some variants are tolerated by TCR-glycolipid-CD1d interaction [31,32]. Various modifications at C-6 of the sugar portion using the amino group $[26,29,33]$ in both synthetic and library fashion for SAR elaboration have been reported in the literature $[12,20]$. For diversifying the compound pools, a library approach could provide a straightforward manner. Recent development of $\alpha$-GalCer libraries including the solution-phasesynthesis approach of Wong [12] and the solid phase synthesis approach of Howell [20] have generated a number of compounds. Both purity and identity can be achieved in this approach.

Recently, 6'-azidogalactosyl 2-aminosphingosine analogs and their relevant galactosyl ceramide analogs were prepared by using a delicate synthetic design [33]. By employing sophisticated glycosylation conditions [34-36], a reactive silyl protected 1-iodogalactoside as donor could be coupled with less reactive acceptors to provide $\alpha$-GalCer in a good yield and in exclusive $\alpha$-stereoselective fashion. 
Scheme 1. Panel (A) $\alpha$-GalCer and structural analogue with stable glycosidic bond may resist metabolic cleavage. Panel (B) Structural modification using amide may resist metabolic cleavage. The library moieties to be prepared may modify the cytotoxicity as well as immunostimulating effect.

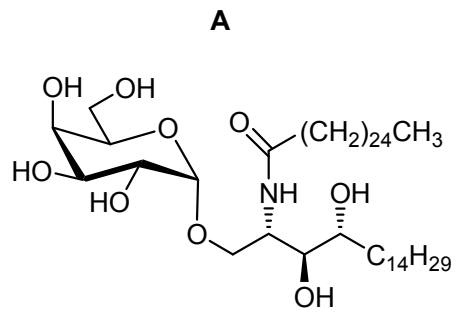

a-GalCer or KRN7000

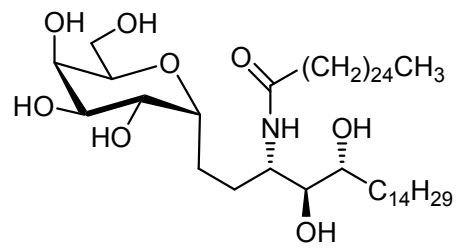

C-glycoside analogue

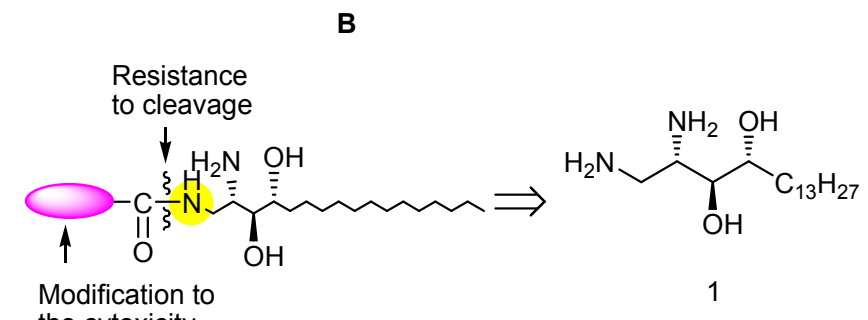

the cytoxicity

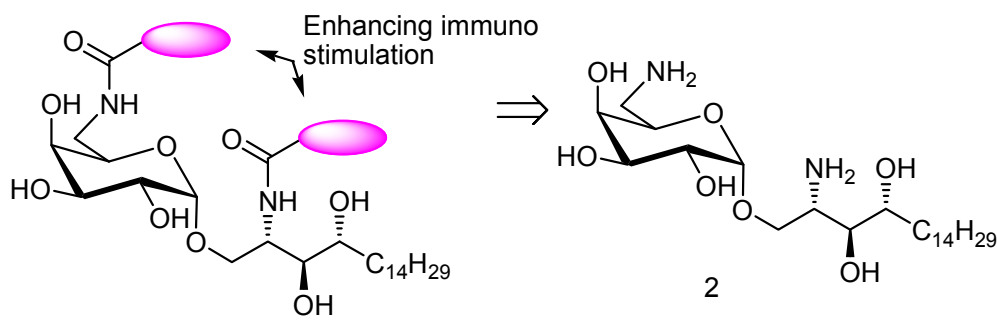

In addition, glycosylation using imidates [37], thiosugars [38], and fluorosugars [31] have been well-documented. These results indicate that the glycosylation is very sensitive and depends heavily on the matching reactivities between donors and acceptors [34]. Satisfactory yield and $\alpha$-selectivity could be achieved through glycosylation of an armed donor and disarmed acceptor. The present work comprised three parts: (1) the preparation of a novel 1,2-diamino phytosphingosine; (2) preparation of 6-azido thiogalactoside with ester-type and ether-type donors for obtaining glycosylated compounds in both acceptable yield and stereoselectivity; and (3) the in-situ screening [39-41] of the cellular cytotoxicity and the validation of the purified compounds [42].

\section{Results and Discussion}

Both commercially available [43] and well-protected phytosphingosine [44] obtained from the Garner aldehyde [45] were used as starting materials to prepare the target compounds $\mathbf{2}$ and $\mathbf{1}$ (Scheme 2). Thus, the current synthetic strategy attempted to use the azide group as a masked functionality for both the phytosphingosine base and sugar portion.

The azido-compound [46] was introduced under a mild reaction conditions using copper-catalysis (Scheme 3). The subsequent introduction of the triflate did not lead to the desired product 5 but only the cyclized analog of 2-epi-jaspin B (6), a reported recently potential anti-cancer compound [47]. Whereas the triflate is a very good leaving group with a potency of 100 times than that of tosylate [48], the leaving tendency was insufficient to induce the desired ring closure. A trace amount of acid generated during the chromatography might weaken the ether protecting group [49]. On the other hand, the intramolecular $\mathrm{SN}_{2}$ reaction mediated by a suitable stereochemistry has been addressed [50]. In the present case, the nucleophilicity of the OBn group might be displayed by orienting itself through a conformational change of the backbone as evidenced from the ${ }^{1} \mathrm{H}-\mathrm{NMR}$ in the preparations. Hence, 
the complex between the five-membered cation and the triflate was converted to the neutral 2-epi jaspin B 6 along with the benzyl cation stabilized by the resonance contributors (Scheme 3).

Scheme 2. Preparation of the starting materials 3, 12 for the present study.

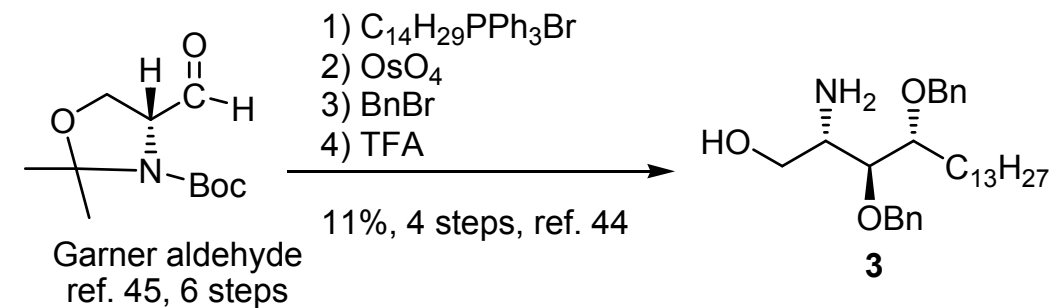

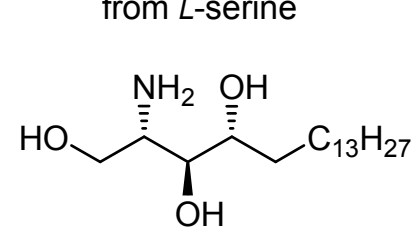

phytosphingosine

1) $\mathrm{TfN}_{3}$

2) $\mathrm{TBDMSCl}$

3) $\mathrm{BzCl}$

4) HF pyr.

$41 \%, 4$ steps

ref. 43

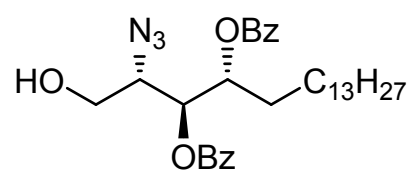

12

Scheme 3. Unexpected ring closure during the preparation of triflate compound $\mathbf{5}$ and the probable mechanism that leads to its formation.

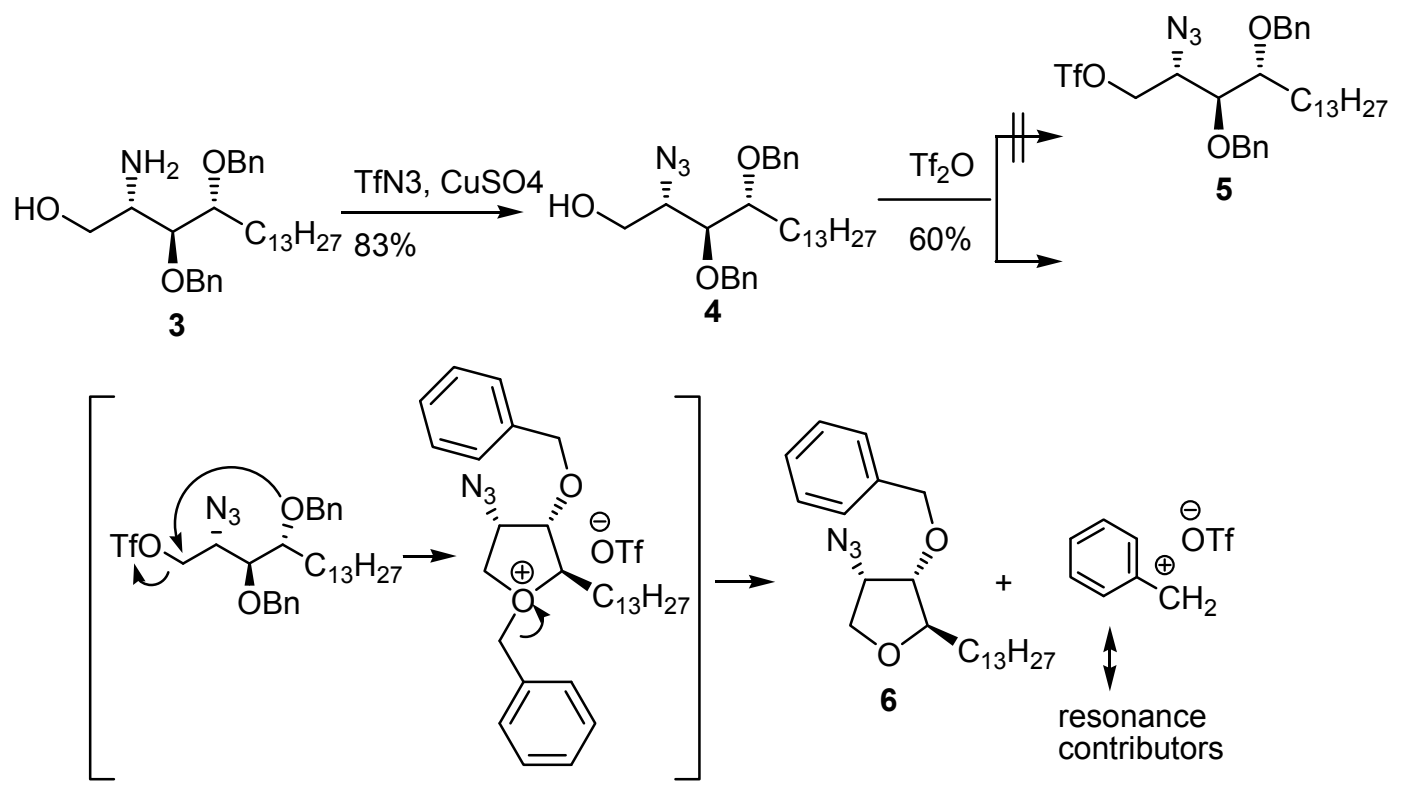

Introduction of the tosyl group using tosyl chloride took place smoothly without encountering the problem of ring closure (Scheme 4). The subsequent nucleophilic attack by azide afforded the desired diazido compound $\mathbf{8}$ in $80 \%$ yield accompanied with the cyclized 2-epi-jaspin B analog $\mathbf{6}$. The following reduction using $\mathrm{BCl}_{3}$ gave the desired diaminophytosphingosine analog $\mathbf{1}$ in quantitative yield. Interestingly, when using less equivalents of $\mathrm{BCl}_{3}$ (5 eq.), the primary azide was selectively reduced to afford the monoamino compound 9. The probable cause for the partial reduction of the protecting groups is proposed to be deactivation of the remaining unreacted $\mathrm{BCl}_{3}$ to form a complex with the reduced amino group and to a slight extent with the oxo groups (Scheme 4) [51,52]. 
Scheme 4. Preparation of the 1,2-diamino and 1-amino-2-azido phytosphingosine analogs 1 and 9. Formation of the complex proposed to explain the partial reduction of the azido group when using 5 equivalents of $\mathrm{BCl}_{3}$.

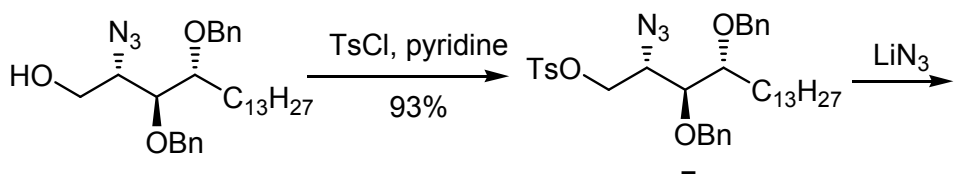

4

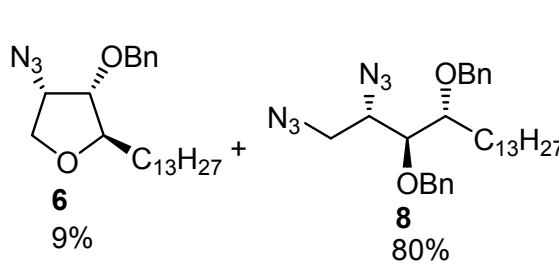

7

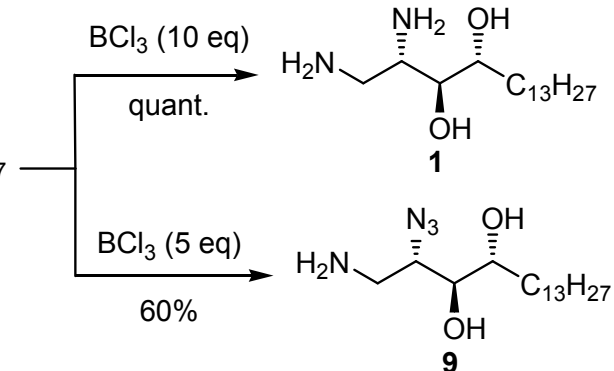

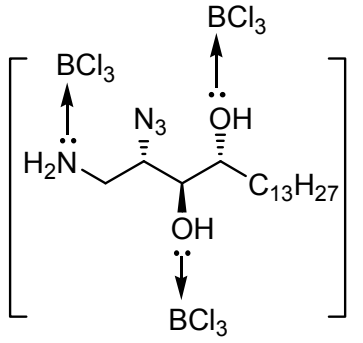

As observed in the ${ }^{1} \mathrm{H}-\mathrm{NMR}$ for the diamino compound 1, the two broad peaks at 8.26 and 8.47 ppm indicated the presence of ammonium complexes. Although both ${ }^{1} \mathrm{H}$ - and ${ }^{13} \mathrm{C}-\mathrm{NMR}$ spectra for the slightly-light-brown sample were satisfactory, the compound could be purified to a white solid by elution from an ion exchange $\left(\mathrm{OH}^{-}\right)$resin.

For synthesizing the galactosyl phytosphingosine, the 6-azido galactosyl thioglycoside $\mathbf{1 0}$ was used as a donor (Figure 1) [53-56]. Glycosylation using both ether-protected donor and acceptor, the so-called "armed glycosylation" [57-59], could deliver products $14 \alpha, \beta$ in high yield but with diminished stereoselectivity (Table 1, entry 1). On the other hand, glycosylation using benzoylprotected sphingosine 12, a disarmed acceptor, could provide products $\mathbf{1 5}$ in fair yield but slightly improved selectivity (entry 2). This might be attributed to an oxocarbenium ion preformed before the nucleophilic attack by lipid [59]. When a benzyl-protected ceramide 13 [44] was used as an acceptor, only very limited amounts of the glycosylated product 16 were obtained (Table 1, entry 3). The poor yield could be due to the neighboring amido hydrogen donor that decreases the nucleophilicity of the primary alcohol, which has been well documented in the literature [60]. It has been reported that imidate as a donor could achieve excellent yields and $\alpha$-stereoselectivity in glycosylation [36]. By adopting similar conditions, only the undesired silylated alcohol was obtained, whereas the imidate was consumed (Table 1, entry 4). A similar result was obtained when using ceramide $\mathbf{1 3}$ as an acceptor (entry 5); the problem there might be caused by the discrepancy in reactivity between acceptor and donor.

Although the concomitant reduction for both benzyl and azido groups of galactosyl sphingosine was difficult [61], compound 14 could be fully deprotected by using the reagent combination of $\mathrm{H}_{2}$, $\mathrm{MeOH} / \mathrm{CHCl}_{3}, \mathrm{AcOH}$ and $\mathrm{Pd}(\mathrm{OH})_{2}$. For example, the $\beta$-anomer $\mathbf{1 4} \beta$ was used to test this condition and the deprotected product 17 could be obtained in $86 \%$ yield (Figure 6). For comparing with the 18-carbon-based KRN7000, the galactosyl sphingosine $\mathbf{2}$ was used as another core compound (Scheme 5). Its preparation is relatively straightforward through a stepwise removal of both ester- and ether-protecting groups. Since the more accessible core compound $\mathbf{1}$ was obtained in sufficient quantity, it provided adequate amounts for further elaboration of amide products (Scheme 6) and for screening cytotoxicities. 
Figure 1. Donors and acceptors used for preparing glycosylated products.

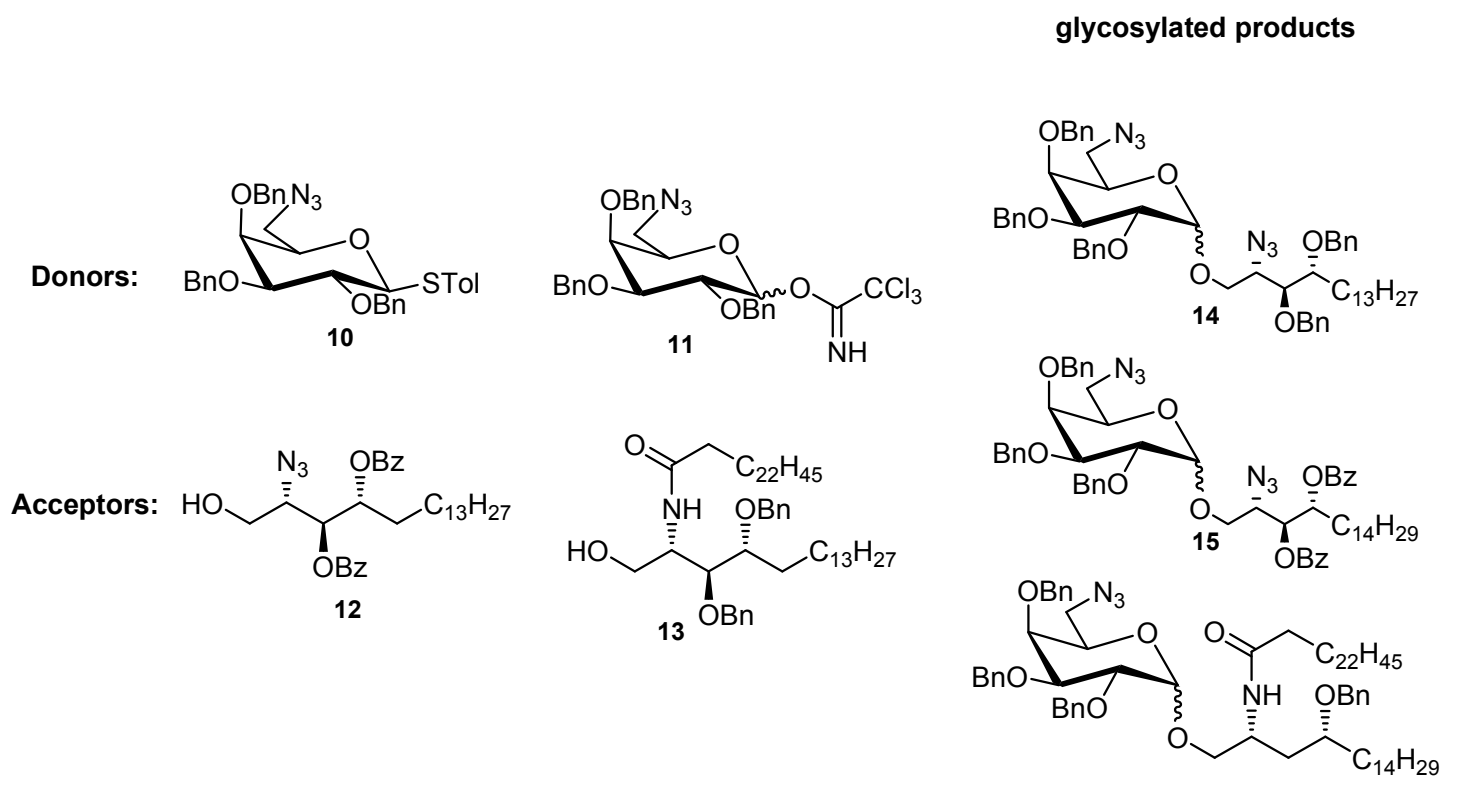

Table 1. Glycosylation between sphingosine analogs 4, 12, 13 and 6-azido galactosyl donors 10, 11 under armed or disarmed conditions.

\begin{tabular}{lllllll}
\hline Entry & Donor & Acceptor & Time & Product & Yield & $\alpha / \beta$ \\
\hline $1^{\dagger}$ & $\mathbf{1 0}$ & $\mathbf{4}$ & $30 \mathrm{~min}$ & $\mathbf{1 4}$ & $95 \%$ & $51 / 44$ \\
$2^{\ddagger}$ & $\mathbf{1 0}$ & $\mathbf{1 2}$ & $1 \mathrm{~h}$ & $\mathbf{1 5}$ & $65 \%$ & $2 / 1$ \\
$3^{\S}$ & $\mathbf{1 0}$ & $\mathbf{1 3}$ & $1 \mathrm{~h}$ & $\mathbf{1 6}$ & $<2 \%$ & N.A. \\
$4^{¥}$ & $\mathbf{1 1}$ & $\mathbf{1 2}$ & $1 \mathrm{~h}$ & $\mathbf{1 5}$ & N.F. & N.A. \\
$5^{¥}$ & $\mathbf{1 1}$ & $\mathbf{1 3}$ & $1 \mathrm{~h}$ & $\mathbf{1 6}$ & N.O. & N.A. \\
\hline
\end{tabular}

${ }^{\dagger} \mathrm{NIS}$ and TfOH (cat.) under $0{ }^{\circ} \mathrm{C}$ was used; ${ }^{*} \mathrm{NIS}$ and TfOH (cat.) under $-78{ }^{\circ} \mathrm{C} \rightarrow-20{ }^{\circ} \mathrm{C}$ was used; ${ }^{\S}$ The presence of the products was confirmed by ESI-MS; ${ }^{¥}$ TMSOTf and co-solvents: $\mathrm{Et}_{2} \mathrm{O} / \mathrm{THF}$ 5:1 under $-23{ }^{\circ} \mathrm{C}$ was used. N.A.: not available; N.O.: not observed; N.F.: not formed but only a silylated acceptor byproduct was obtained.

Scheme 5. Concomitant removal of benzoyl and benzyl groups using reagent combination.

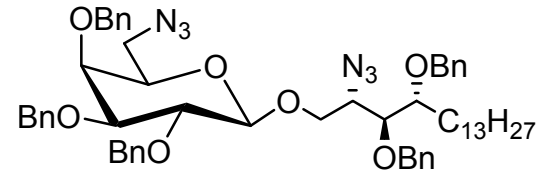

$14 \beta$

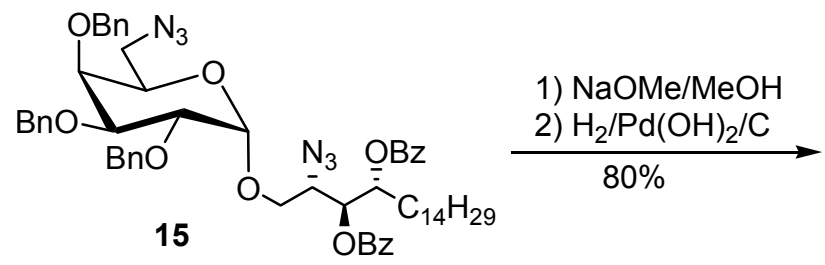

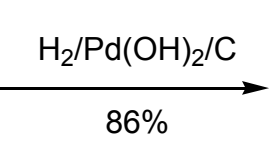

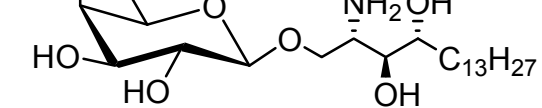

$17 \beta$

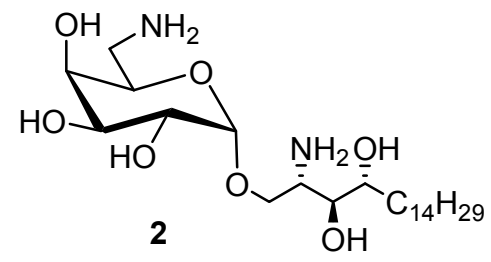


Scheme 6. The concept for parallel solution phase synthesis of library for the cytotoxicity screening and further validation for iNKT cell inducing experiment.

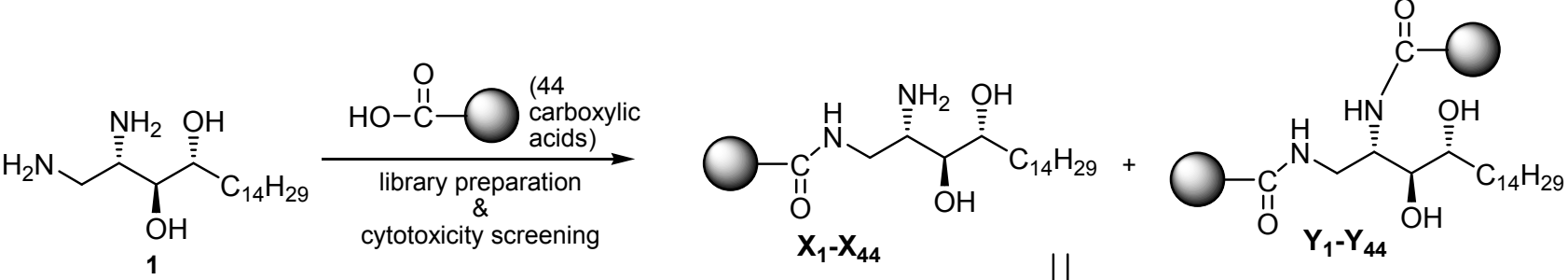

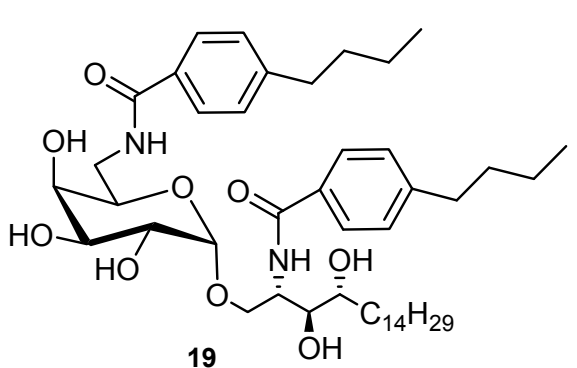

The subsequent library preparation started from core compound $\mathbf{1}(20 \mathrm{mg})$ by coupling with 44 carboxylic acids using equivalent molarities (Figure 2 and reference $[39,40]$ ).

Figure 2. Carboxylic acids used for amide library preparation.
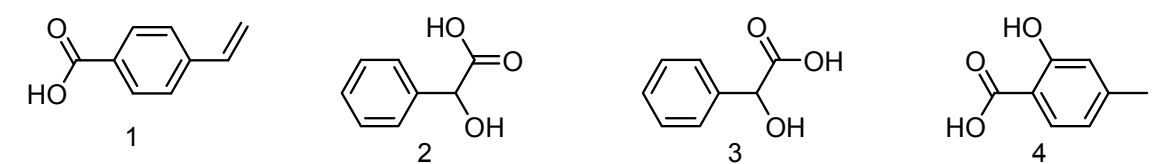<smiles>O=C(O)Cc1ccc(O)cc1</smiles><smiles>CNc1ccc(C(=O)O)cc1</smiles><smiles>O=C(O)C/C=C/c1ccccc1</smiles><smiles>O=C(O)CNc1ccc(O)cc1</smiles><smiles>COc1ccc(C(=O)O)cc1O</smiles>

9<smiles>COc1ccccc1C(=O)O</smiles>

10<smiles>CCCCc1ccc(C(=O)O)cc1</smiles>

11<smiles>[Y7]c1c(C(=O)O)cccc1[N+](=O)[O-]</smiles><smiles>O=C(O)c1cc([N+](=O)[O-])ccc1O</smiles>

13<smiles>Nc1ccc(C(=O)NCC(=O)O)cc1</smiles><smiles>COc1cc(C=CC(=O)O)ccc1O</smiles>

15<smiles>O=C(NC(O)C(=O)O)c1ccccc1</smiles>

16<smiles>COC(=O)Cc1ccc(CC(C)C)cc1</smiles>

17<smiles>CC(C)(C)c1cc(C(=O)O)cc(C(C)(C)C)c1O</smiles><smiles>COc1cc(C(=O)O)cc(OC)c1OC</smiles><smiles>Cc1ccc(C)c(OCCCC(C)(C)C(=O)O)c1</smiles>

22<smiles>O=C(O)C(c1ccccc1)c1ccccc1</smiles>

19<smiles>C=C(C)C1CC=C(C)C(N)(C(=O)O)C1</smiles>

23<smiles>O=C(O)CNC(=O)c1ccc([N+](=O)[O-])cc1</smiles>

20<smiles>O=C1CC[C@H](C(=O)O)N1</smiles> 
Figure 2. Cont.

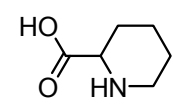

25
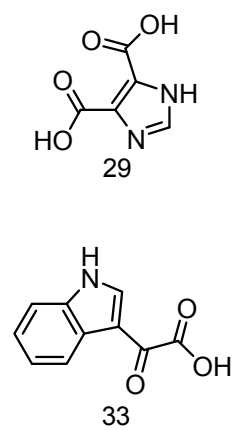

33<smiles>O=C(O)c1ccccc1C(c1ccc(O)cc1)c1ccc([Se])cc1</smiles><smiles>O=C(O)CCC(=O)c1ccc(-c2ccccc2)cc1</smiles>

38<smiles>O=C(O)c1ccc([N+](=O)[O-])o1</smiles><smiles>O=C(O)CCc1c[nH]c2ccccc12</smiles><smiles>Nc1ccc(C(=O)O)cn1</smiles>

27<smiles>Cn1c(C(=O)O)cc2ccccc21</smiles>

31<smiles>CC(C)(C)OC(=O)N1CCCC1C(=O)O</smiles><smiles>O=C(O)c1ncccc1O</smiles>

28<smiles>O=C(O)/C=C/c1c[nH]c2ccccc12</smiles>

36<smiles>CCn1cc(C(=O)O)c(=O)c2cnc(N3CCNCC3)nc21</smiles>

40<smiles>Nc1ccc(C(=O)O)c(Cl)c1</smiles><smiles>Nc1cc(Cl)ccc1C(=O)O</smiles>

The initial screening for the cytotoxicities of these amide product mixtures was performed by using an MTT assay with normal tissue derived fibroblast cells. Analog $\mathbf{1 8}$ showed less cytotoxicity against normal human fibroblasts ( $50 \%$ cell viability $v s .0-5 \%$ of other analogs in U87 cells).

Scheme 7. Independent preparation of the potential amide products $\mathbf{1 8}$ and $\mathbf{1 9}$ followed by purification with HPLC.<smiles>[14CH3][C@@H](O)[C@@H](O)[C@H](N)CN</smiles>

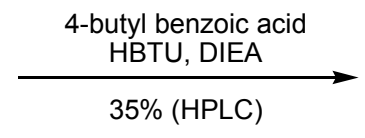

1

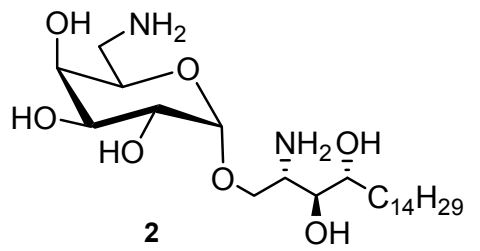

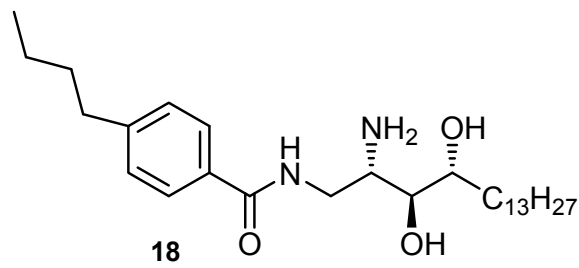

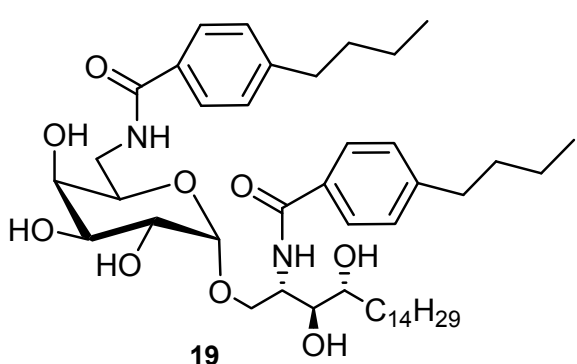


The less toxic product mixtures were further examined. These sample mixtures after simple filtration through silica gel were submitted to analysis with ESI-MS. Five product samples showed the expected molecular ion peak patterns, respectively (Supplementary Information). Among them, the 4-butylbenzoic acid derived amide product showing the most significant signals was resynthesized in both its ceramide form 18 and galactosyl ceramide form 19 (Scheme 7).

The subsequent validation experiment was performed by MTT assay and flow cytotmetry (Figure 3). Interestingly, $\alpha$-GalCer analog 19 was V $\alpha 24+/ \mathrm{V} \beta 11+\mathrm{iNKT}$ cell-stimulative but less cytotoxic compound 18 did not show an equivalent activity. This confirmed the important role played by the sugar moieties. Hence, libraries based on galactosyl phytosphingosine analog $\mathbf{2}$ warrant further study.

Figure 3. Potencies of analogs 18 and 19 for stimulation of human V $\alpha 24+/ V-\beta 11+$ NKT cell populations. Peripheral blood mononuclear cells (PBMC) from a normal healthy donor were incubated with each individual compound at a final concentration of $100 \mathrm{nM}$. After 14 days of culture, NKT cell frequencies were determined by flow cytometry. NKT cell frequencies were defined as the percentage of $\mathrm{V} \alpha 24+/ \mathrm{V}-\beta 11+$ cells among gated lymphocytes in the upper right (UR) corner for each case. Shown here are the profiles of PBMC harvested from 14-day cultures containing (a) vehicle alone (DMSO, UN); or (b) $100 \mathrm{nM}$ of $\alpha$-GalCer (KS); (c) analog 18 (DABB); or (d) analog 19 (DAGBB), as indicated.
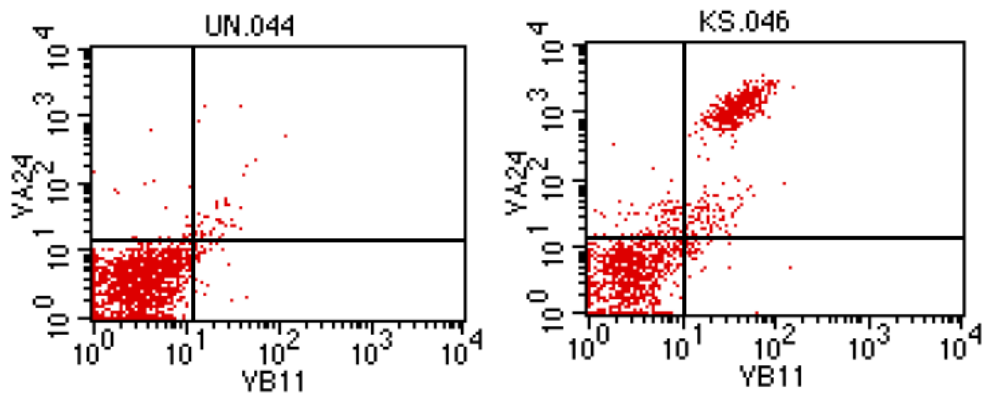

(a) $\mathrm{UR}=3.13 \%$

(b) UR $=35.3 \%$
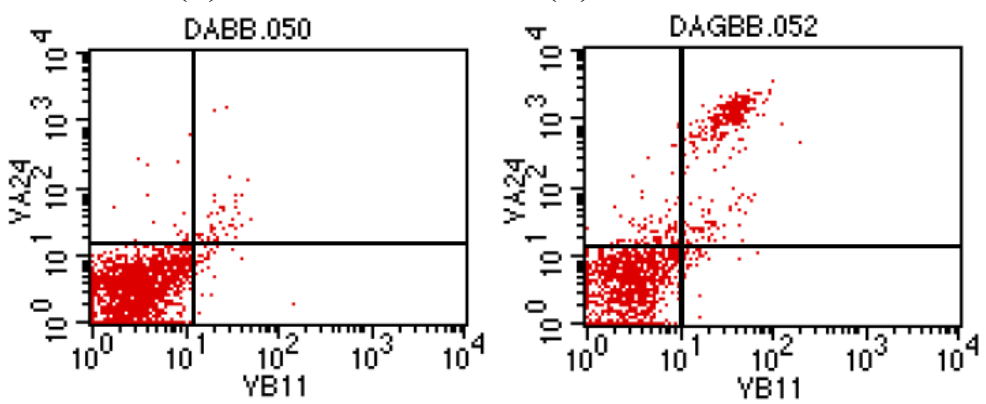

(c) $\mathrm{UR}=2.63 \%$

(d) $\mathrm{UR}=18.3 \%$

\section{Experimental}

\subsection{General}

All reagents and solvents were purchased from Sigma-Aldrich, Mallinckrodt, Acros, Alfa, Tedia, or Fluka. All preparations for nonradioactive compounds were routinely conducted in dried glassware under a positive pressure of nitrogen at room temperature unless otherwise noted. $\mathrm{CH}_{2} \mathrm{Cl}_{2}$, toluene, $\mathrm{CH}_{3} \mathrm{CN}$, and pyridine were dried over $\mathrm{CaH}_{2}$ and $\mathrm{MeOH}$ was dried over $\mathrm{Mg}$ and distilled prior to 
reaction. DMF and $\mathrm{NEt}_{3}$ were distilled under reduced pressure. Reagents and solvents were of reagent grade. Dimethylaminopyridine (DMAP) was purified through recrystallization from the combination of EtOAc and $n$-hexane before use. The eluents for chromatography: EtOAc, acetone, and $n$-hexane were reagent grade and distilled prior to use; $\mathrm{MeOH}$ and $\mathrm{CHCl}_{3}$ were reagent grade and used without further purification. NMR spectra including ${ }^{1} \mathrm{H}-\mathrm{NMR}$ (500 MHz) and ${ }^{13} \mathrm{C}-\mathrm{NMR}$ (125 MHz, DEPT-135) was measured on a Varian Unity Inova $500 \mathrm{MHz}$ instrument. D-solvents employed for NMR including $\mathrm{CD}_{3} \mathrm{OD}, \mathrm{CDCl}_{3}, \mathrm{C}_{6} \mathrm{D}_{6}$, and DMSO- $\mathrm{d}_{6}$ were purchased from Cambridge Isotope Laboratories, Inc. Low-resolution mass spectrometry (LRMS) was performed on a ESI-MS spectrometry employing VARIAN 901-MS Liquid Chromatography Tandem Mass Q-Tof Spectrometer was performed at the department of chemistry of National Tsing-Hua University (NTHU). High-resolution mass spectrometry (HRMS) was performed using a varian HPLC (Prostar series ESI/APCI) coupled with a Varian 901-MS (FT-ICR Mass) mass detector and triple quadrapole. Elemental analysis was performed using a Foss Heraeus CHN-O-RAPID elemental analysis apparatus. Thin layer chromatography (TLC) was performed with Merck TLC Silica gel $60 \mathrm{~F}_{254}$ precoated plates. The starting materials and products were visualized with UV light $(254 \mathrm{~nm})$. Further confirmation was carried out by using staining with $5 \% p$-anisaldehyde, ninhydrin or ceric ammonium molybdate under heating. Flash chromatography was performed using Geduran Si 60 silica gel (230-400 mesh). Melting points were measured with a MEL-TEMP apparatus and were uncorrected. Flow cytometry was carried out by using a BD FACSCalibur ${ }^{\mathrm{TM}}$.

\subsection{Synthesis of the Compounds}

(2S,3S,4R)-2-Azido-3,4-bis(benzyloxy)heptadecan-1-ol (4): A solution of $\mathrm{NaN}_{3}$ (6 g, 90 mmol, 15 eq.) in water $(15 \mathrm{~mL})$ and $\mathrm{CH}_{2} \mathrm{Cl}_{2}(15 \mathrm{~mL})$ was stirred vigorously at $0{ }^{\circ} \mathrm{C}$. An ice-cold solution of $\mathrm{Tf}_{2} \mathrm{O}$ (5 mL, 30 mmol, 5 eq.) in $\mathrm{CH}_{2} \mathrm{Cl}_{2}\left(5 \mathrm{~mL}\right.$ ) was added to $\mathrm{NaN}_{3}$ (aq.) within 1 min. The solution was vigorously stirred for $2 \mathrm{~h}$ and the water phase turned pale yellow. The organic layer was collected and the aqueous phase was further washed with $\mathrm{CH}_{2} \mathrm{Cl}_{2}(7 \mathrm{~mL} \times 2)$. The organic layer combined was washed with saturated $\mathrm{Na}_{2} \mathrm{CO}_{3}(15 \mathrm{~mL})$. To a solution of compound 3 (2.8 g, $\left.6.2 \mathrm{mmol}\right)$ in $\mathrm{MeOH}$ ( $40 \mathrm{~mL}$ ) was added a solution of $\mathrm{K}_{2} \mathrm{CO}_{3}$ (2 eq., $\left.0.012 \mathrm{~mol}, 1.7 \mathrm{~g}\right)$ and $\mathrm{CuSO}_{4} \cdot 5 \mathrm{H}_{2} \mathrm{O}(15 \mathrm{mg}, 0.06 \mathrm{mmol}$, 0.01 eq.) in $\mathrm{H}_{2} \mathrm{O}(40 \mathrm{~mL})$, sequentially. The solution of $\mathrm{TfN}_{3}$ described above was added and the color turned to blue-green. The stirring at $\mathrm{rt}$ was lasted for $16 \mathrm{~h}$. TLC $\left(\mathrm{MeOH} / \mathrm{CHCl}_{3}=1 / 19\right)$ indicated the consumption of starting material $3\left(\mathrm{R}_{f}=0.29\right)$ and the formation of the product $4\left(\mathrm{R}_{f}=0.79\right)$. The mixture was extracted with EtOAc $(40 \mathrm{~mL} \times 3)$. The organic layer collected was dried with $\mathrm{Na}_{2} \mathrm{SO}_{4}$ and concentrated under reduced pressure. The residue was purified by flash chromatography using silica gel (140 g) with EtOAc/ $n$-hexane $=1: 19$ as eluent to provide a colorless oil with a pleasant odor in $83 \%$ yield $(2.43 \mathrm{~g}) .{ }^{1} \mathrm{H}-\mathrm{NMR}\left(\mathrm{C}_{6} \mathrm{D}_{6}\right): \delta 0.91\left(\mathrm{t}, J=7.0 \mathrm{~Hz}, 3 \mathrm{H}, \mathrm{H}_{\text {aliphatic }}\right), 1.20-1.40(\mathrm{~m}, 21 \mathrm{H}$, $\mathrm{H}_{\text {aliphatic }}$ ), 1.44-1.56 (m, 2H, $\left.\mathrm{H}_{\text {aliphatic }}\right), 1.64$ (bs, $\left.1 \mathrm{H}, \mathrm{H}_{\mathrm{OH}}\right), 1.70-1.80$ (m, 1H, $\left.\mathrm{H}_{\text {aliphatic }}\right), 3.48$ (q, $J=5.0 \mathrm{~Hz}$, $\left.1 \mathrm{H}, \mathrm{H}_{4}\right), 3.60-3.76\left(\mathrm{~m}, 4 \mathrm{H}, \mathrm{H}_{1}, \mathrm{H}_{2}, \mathrm{H}_{3}\right), 4.37\left(\mathrm{~d}, J_{\text {gem }}=12.0 \mathrm{~Hz}, 1 \mathrm{H}, \mathrm{H}_{\mathrm{Bn}}\right), 4.46\left(\mathrm{t}, J_{\text {gem }}=12.0 \mathrm{~Hz}, 1 \mathrm{H}\right.$, $\left.\mathrm{H}_{\mathrm{Bn}}\right), 4.48\left(\mathrm{t}, J_{\text {gem }}=12.0 \mathrm{~Hz}, 1 \mathrm{H}, \mathrm{H}_{\mathrm{Bn}}\right), 4.56\left(\mathrm{~d}, J_{\text {gem }}=11.5 \mathrm{~Hz}, 1 \mathrm{H}, \mathrm{H}_{\mathrm{Bn}}\right), 6.98-7.32\left(\mathrm{~m}, 10 \mathrm{H}, \mathrm{H}_{\mathrm{Bn}}\right)$; ${ }^{13} \mathrm{C}-\mathrm{NMR}\left(\mathrm{C}_{6} \mathrm{D}_{6}\right): \delta 14.33\left(\mathrm{CH}_{3}\right) ; \mathrm{CH}_{2}: 23.08,25.89,29.37,29.52,29.80,30.16,30.37,32.31 ; 62.67$ $\left(\mathrm{CH}_{2}, \mathrm{C}_{1}\right), 63.80\left(\mathrm{CH}, \mathrm{C}_{2}\right), 72.43\left(\mathrm{CH}_{2}, \underline{\mathrm{CH}_{2}} \mathrm{Ph}\right), 73.76\left(\underline{\mathrm{CH}}_{2}, \mathrm{CH}_{2} \mathrm{Ph}\right), 79.58\left(\mathrm{CH}, \mathrm{C}_{4}\right), 80.03\left(\mathrm{CH}, \mathrm{C}_{3}\right)$, $127.90(\mathrm{CH}, \mathrm{Ph}), 128.03(\mathrm{CH}, \mathrm{Ph}), 128.12(\mathrm{CH}, \mathrm{Ph}), 128.25(\mathrm{CH}, \mathrm{Ph}), 128.32(\mathrm{CH}, \mathrm{Ph}), 128.63(\mathrm{CH}$, 
$\mathrm{Ph}), 128.65(\mathrm{CH}, \mathrm{Ph}), 138.52(\mathrm{C}, \mathrm{Ph}), 138.79(\mathrm{C}, \mathrm{Ph})$; LRMS $(\mathrm{m} / \mathrm{z})$ for $\mathrm{C}_{31} \mathrm{H}_{47} \mathrm{~N}_{3} \mathrm{O}_{3}: \mathrm{M}$ (calcd.) = 509.4 $(\mathrm{m} / \mathrm{z}), \mathrm{ESI}+\mathrm{Q}-\mathrm{TOF}: \mathrm{M}=509.3(\mathrm{~m} / \mathrm{z}),\left[\mathrm{M}-\mathrm{N}_{2}-\mathrm{Ph}^{-}\right]^{+}=404.3(100 \%), 405.4$ (28\%), 406.4 (4\%); $[\mathrm{M}+\mathrm{H}]^{+}=510.3(41 \%), 511.4(10 \%) ;[\mathrm{M}+\mathrm{Na}]^{-}=532.3(56 \%), 533.3(18 \%)$, equivalent to the calculated isotopic ratio; analysis (calcd., found for $\left.\mathrm{C}_{31} \mathrm{H}_{47} \mathrm{~N}_{3} \mathrm{O}_{3}\right)$ : $\mathrm{C}(73.05,72.74), \mathrm{H}(9.29,9.09), \mathrm{N}(8.24,8.21)$.

(2R,3S,4S)-4-Azido-3-(benzyloxy)-2-tridecyltetrahydrofuran (6): Compound 4 (7 mg, $0.013 \mathrm{mmol}$ ) was coevaporated with toluene three times, followed by dissolving in $\mathrm{CH}_{2} \mathrm{Cl}_{2}(1 \mathrm{~mL})$. Upon the cooling down to $-50{ }^{\circ} \mathrm{C}$, pyridine $(5 \mu \mathrm{L}, 0.06 \mathrm{mmol}, 5$ eq. $)$ and $\mathrm{Tf}_{2} \mathrm{O}(4 \mu \mathrm{L}, 0.03 \mathrm{mmol}, 2$ eq. $)$ were added sequentially. The reaction was lasted for $30 \mathrm{~min}$. TLC (EtOAc/n-hexane $=1: 9)$ indicated the consumption of the starting material $4\left(\mathrm{R}_{f}=0.21\right)$ and the formation of the product $6\left(\mathrm{R}_{f}=0.55\right)$. $\mathrm{CH}_{2} \mathrm{Cl}_{2}(10 \mathrm{~mL})$ was added and the mixture was extracted by saturated aqueous $\mathrm{NH}_{4} \mathrm{Cl}(5 \mathrm{~mL})$ and $\mathrm{H}_{2} \mathrm{O}(5 \mathrm{~mL} \times 2)$. The organic layer collected was dried with $\mathrm{Na}_{2} \mathrm{SO}_{4}$ and concentrated under reduced pressure. The residue was purified with flash chromatography using eluents of EtOAc/ $n$-hexane $=1: 19$ and silica gel $(4 \mathrm{~g})$ to provide product 6 in $60 \%$ yield $(3 \mathrm{mg})$. For analytical purpose, a small amount sample $(20 \mathrm{mg})$ was obtained via another route as described for the preparation of compound $\mathbf{8}$. In rare cases, we were able to isolate the triflate 5. The fragment peaks appeared in ESI-MS spectrum such as $479.3 \mathrm{amu}(27 \%), 493.4 \mathrm{amu}(2.4 \%)$ and $595.6 \mathrm{amu}(2.4 \%)$ indicated that the instability of triflate could lead to a number of intermediates. Satisfactory ${ }^{1} \mathrm{H}-\mathrm{NMR}$ spectra were, however, not available due to the complex patterns. ${ }^{1} \mathrm{H}-\mathrm{NMR}\left(\mathrm{C}_{6} \mathrm{D}_{6}\right): \delta 0.91\left(\mathrm{t}, J=7.0 \mathrm{~Hz}, 3 \mathrm{H}, \mathrm{H}_{\text {aliphatic }}\right), 1.23-1.36(\mathrm{~m}, 21 \mathrm{H}$, $\mathrm{H}_{\text {aliphatic }}$ ), $1.38-1.49$ (m, $\left.3 \mathrm{H}, \mathrm{H}_{\text {aliphatic }}\right), 3.17\left(\mathrm{ddd}, J_{4,3}=6.0, J_{4,5 a}=5.5, J_{4,5 b}=5.5 \mathrm{~Hz}, 1 \mathrm{H}, \mathrm{H}_{4}\right), 3.31$ (dd, $\left.1 \mathrm{H}, J_{3,2}=6.5, J_{3,4}=6.0 \mathrm{~Hz}, 1 \mathrm{H}, \mathrm{H}_{3}\right), 3.60\left(\mathrm{dd}, J_{1 a, l b}=10.0, J_{1 a, 2}=5.5 \mathrm{~Hz}, 1 \mathrm{H}, \mathrm{H}_{1 \mathrm{a}}\right), 3.68(\mathrm{dd}$, $\left.J_{l b, 1 a}=10.0, J_{1 b, 2}=3.5 \mathrm{~Hz}, 1 \mathrm{H}, \mathrm{H}_{1 \mathrm{a}}\right), 3.96\left(\mathrm{ddd}, J_{2,3}=6.5, J_{2,1 a}=5.5, J_{2,1 b}=3.5 \mathrm{~Hz}, 1 \mathrm{H}, \mathrm{H}_{2}\right), 4.21(\mathrm{~d}$, $\left.1 \mathrm{H}, J_{\text {gem }}=11.5 \mathrm{~Hz}, \mathrm{OC} \underline{H} \mathrm{HPh}\right), 4.48\left(\mathrm{~d}, 1 \mathrm{H}, J_{\text {gem }}=11.5 \mathrm{~Hz}, \mathrm{OCH} \underline{H \mathrm{Ph}}\right), 7.08-7.11(\mathrm{~m}, 1 \mathrm{H}, \mathrm{Ph})$, 7.17-7.19 (m, 2H, Ph), 7.29-7.31 (m, 2H, Ph); ${ }^{13} \mathrm{C}-\mathrm{NMR}\left(\mathrm{C}_{6} \mathrm{D}_{6}\right): \delta 14.33\left(\mathrm{CH}_{3}\right) ; \mathrm{CH}_{2}: 23.08,26.17$, 29.79, 30.01, 30.10, 30.13, 32.30, 34.05; $60.69\left(\mathrm{CH}, \mathrm{C}_{2}\right), 69.79\left(\mathrm{CH}_{2}, \mathrm{C}_{1}\right), 72.81\left(\underline{\mathrm{CH}}_{2}, \mathrm{CH}_{2} \mathrm{Ph}\right), 81.13$ $\left(\mathrm{CH}, \mathrm{C}_{4}\right), 84.03\left(\mathrm{CH}, \mathrm{C}_{3}\right), 128.04(\mathrm{CH}, \mathrm{Ph}), 128.11(\mathrm{CH}, \mathrm{Ph}), 128.29(\mathrm{CH}, \mathrm{Ph}), 128.65(\mathrm{CH}, \mathrm{Ph})$, $138.08(\mathrm{C}, \mathrm{Ph})$; LRMS $(\mathrm{m} / \mathrm{z})$ for $\mathrm{C}_{24} \mathrm{H}_{39} \mathrm{~N}_{3} \mathrm{O}_{2}$ : $\mathrm{M}(\mathrm{calcd}$.) $=401.3(\mathrm{~m} / \mathrm{z})$; ESI+Q-TOF: $\mathrm{M}=401.3(\mathrm{~m} / \mathrm{z})$, $\mathrm{M}^{+}-\mathrm{N}_{2}-\mathrm{Ph}+\mathrm{H}^{-}=\mathrm{M}^{\prime},\left[2 \mathrm{M}^{\prime}+\mathrm{H}\right]^{+}=595.59 ;[\mathrm{M}-\mathrm{OTf}+\mathrm{H}]^{+}=493.4 ;[\mathrm{M}-\mathrm{OTf}-\mathrm{N}+\mathrm{H}]^{+}=479.3$.

(2S,3S, 4R)-2-Azido-3,4-bis(benzyloxy)heptadecyl-4-methyl benzenesulfonate (7): Before carrying out the tosylation, $\mathrm{TsCl}$ was purified by partition between toluene and $10 \% \mathrm{NaOH}$ (aq). Compound 4 (2.42 $\mathrm{g}, 4.75 \mathrm{mmol})$ was azeotropically distilled with toluene for three times, followed by dissolving in $\mathrm{CH}_{2} \mathrm{Cl}_{2}(75 \mathrm{~mL})$ under $\mathrm{N}_{2}$ at $0{ }^{\circ} \mathrm{C}$. Pyridine $(75 \mathrm{~mL})$ and $p$ - $\mathrm{TsCl}(1.81 \mathrm{~g}, 9.5 \mathrm{mmol})$ were added, sequentially, and the mixture was stirred for $10 \mathrm{~min}$, followed by stirring at $\mathrm{rt}$ for $16 \mathrm{~h}$. TLC (EtOAc/n-hexane $=1: 9)$ indicated the consumption of the starting material $4\left(\mathrm{R}_{f}=0.19\right)$ and the formation of the product $7\left(\mathrm{R}_{f}=0.40\right)$. Following the addition of $\mathrm{H}_{2} \mathrm{O}(100 \mathrm{~mL})$, the aqueous phase was extracted with $\mathrm{CH}_{2} \mathrm{Cl}_{2}(40 \mathrm{~mL} \times 3)$. The organic layer collected was dried with $\mathrm{Na}_{2} \mathrm{SO}_{4}$ and concentrated under reduced pressure. The residue was purified using flash chromatography with eluents of EtOAc/ $n$-hexane $=1 / 19$ and silica gel $(100 \mathrm{~g})$ to provide colorless oil 7 in $93 \%$ yield $(2.94 \mathrm{~g})$. ${ }^{1} \mathrm{H}-\mathrm{NMR}\left(\mathrm{C}_{6} \mathrm{D}_{6}\right): \delta 0.91\left(\mathrm{t}, J=7.0 \mathrm{~Hz}, 3 \mathrm{H}, \mathrm{H}_{\text {aliphatic }}\right), 1.19-1.38(\mathrm{~m}, 22 \mathrm{H}), 1.38-1.46(\mathrm{~m}, 1 \mathrm{H}), 1.61-1.68$ $(\mathrm{m}, 1 \mathrm{H}), 1.79(\mathrm{~s}, 3 \mathrm{H}), 3.48\left(\mathrm{dd}, J_{3,4}=5.0, J_{3,2}=5.0 \mathrm{~Hz}, 1 \mathrm{H}, \mathrm{H}_{3}\right), 3.53\left(\mathrm{ddd}, 1 \mathrm{H}, J_{4,5 a}=7.0, J_{4,5 b}=6.5\right.$, $\left.J_{4,3}=5.0 \mathrm{~Hz}, 1 \mathrm{H}, \mathrm{H}_{4}\right), 3.80\left(\mathrm{ddd}, J_{2,1 a}=7.5, J_{2,3}=5.0, J_{2,1 b}=2.5 \mathrm{~Hz}, 1 \mathrm{H}, \mathrm{H}_{2}\right), 4.28\left(\mathrm{dd}, J_{1 a, 1 b}=10.5\right.$, 
$\left.J_{l a, 2}=7.5 \mathrm{~Hz}, 1 \mathrm{H}, \mathrm{H}_{1 \mathrm{a}}\right), 4.31\left(\mathrm{~d}, 1 \mathrm{H}, J_{g e m}=12.0 \mathrm{~Hz}, \mathrm{OC} \underline{H} \mathrm{HPh}\right), 4.35\left(\mathrm{~d}, 1 \mathrm{H}, J_{g e m}=12.0 \mathrm{~Hz}\right.$, $\mathrm{OCH} \underline{H} \mathrm{Ph}), 4.39(\mathrm{~s}, 2 \mathrm{H}, 2 \times \mathrm{OC} \underline{H} \mathrm{HPh}), 4.46\left(\mathrm{dd}, J_{1 b, 1 a}=10.5, J_{1 b, 2}=2.5 \mathrm{~Hz}, 1 \mathrm{H}, \mathrm{H}_{1 \mathrm{~b}}\right), 6.63-6.64(\mathrm{~m}$, 2H, Ph), 7.06-7.13 (m, 4H, Ph), 7.16-7.21 (m, 4H, Ph), 7.26-7.27 (m, 2H, Ph), 7.74-7.57 (m, 2h, Ph); ${ }^{13} \mathrm{C}-\mathrm{NMR}\left(\mathrm{C}_{6} \mathrm{D}_{6}\right): \delta 14.33\left(\mathrm{CH}_{3}\right) ; 21.11\left(\mathrm{CH}_{3}\right)$; CH2: 23.07, 25.39, 29.79, 30.01, 30.09, 30.14, 30.27, 32.29; $61.60\left(\mathrm{CH}, \mathrm{C}_{2}\right), 69.92\left(\mathrm{CH}_{2}, \mathrm{C}_{1}\right), 72.26\left(\mathrm{CH}_{2}, \underline{\mathrm{CH}}_{2} \mathrm{Ph}\right), 73.52\left(\underline{\mathrm{CH}}_{2}, \mathrm{CH}_{2} \mathrm{Ph}\right), 78.75\left(\mathrm{CH}, \mathrm{C}_{4}\right)$, $79.67\left(\mathrm{CH}, \mathrm{C}_{3}\right), 127.87(\mathrm{CH}, \mathrm{Ph}), 128.04(\mathrm{CH}, \mathrm{Ph}), 128.23(\mathrm{CH}, \mathrm{Ph}), 128.29(\mathrm{CH}, \mathrm{Ph}), 128.62(\mathrm{CH}$, $\mathrm{Ph}), 129.86(\mathrm{CH}, \mathrm{Ph}), 133.80$ (C, tosyl), 138.08 (C, Ph), 138.64 (C, Ph), 144.44 (C, tosyl); LRMS for $\mathrm{C}_{38} \mathrm{H}_{53} \mathrm{~N}_{3} \mathrm{O}_{5} \mathrm{~S}: \mathrm{M}($ calcd. $)=663.4(\mathrm{~m} / \mathrm{z}), \mathrm{MW}=663.9, \mathrm{ESI}+\mathrm{Q}-\mathrm{TOF}: \mathrm{M}=663.3(\mathrm{~m} / \mathrm{z}),[\mathrm{M}+\mathrm{Na}]^{+}=686.3$.

[(2S,3S, 4R)-1,2-Diazidoheptadecane-3,4-diyl)bis(oxy)bis(methylene]dibenzene (8): An aqueous solution of $\mathrm{LiN}_{3}(10.55 \mathrm{~g}, 43.1 \mathrm{mmol}, 20 \% \mathrm{wt}$ in water) was azeotropically distilled with DMF (2 mL) under reduced pressure for two times. The residue was dissolved in DMF $(75 \mathrm{~mL})$ and transferred to a two-necked bottom flask containing a solution of starting material 7 (2.86 g, $4.31 \mathrm{mmol}$ ) in DMF $(75 \mathrm{~mL})$ under $\mathrm{N}_{2}$ at r.t. The mixture was then stirred at $80{ }^{\circ} \mathrm{C}$ for $2 \mathrm{~h}$. TLC $(\mathrm{EtOA} / n$-hexane $=1: 9)$ indicated the consumption of the starting material $7\left(\mathrm{R}_{f}=0.42\right)$ and the formation of the product 8 $\left(\mathrm{R}_{f}=0.55\right)$. The mixture was transferred to a funnel for partition between $\mathrm{H}_{2} \mathrm{O}(75 \mathrm{~mL})$ and EtOAc $(75 \mathrm{~mL})$. The organic layer separated was dried with $\mathrm{Na}_{2} \mathrm{SO}_{4}$ and filtered through a Celite pad. The filtrate was concentrated under reduced pressure. The residue obtained was purified with flash chromatography on silica gel (110 g) using EtOAc/n-hexane 1:39 as eluent to provide 8 as a colorless oil in $80 \%$ yield $(1.81 \mathrm{~g})$ and compound 6 in $9 \%$ yield $(155 \mathrm{mg}) .{ }^{1} \mathrm{H}-\mathrm{NMR}\left(\mathrm{C}_{6} \mathrm{D}_{6}\right): \delta 0.91(\mathrm{t}, J=6.5 \mathrm{~Hz}$, $\left.3 \mathrm{H}, \mathrm{H}_{\text {aliphatic }}\right), 1.22-1.38\left(\mathrm{~m}, 21 \mathrm{H}, \mathrm{H}_{\text {aliphatic }}\right), 1.38-1.52\left(\mathrm{~m}, 2 \mathrm{H}, \mathrm{H}_{\text {aliphatic }}\right), 1.66-1.78\left(\mathrm{~m}, 1 \mathrm{H}, \mathrm{H}_{\text {aliphatic }}\right)$, $3.17\left(\mathrm{~d}, J=5.0 \mathrm{~Hz}, 2 \mathrm{H}, \mathrm{H}_{3}, \mathrm{H}_{4}\right), 3.46-3.56\left(\mathrm{~m}, 3 \mathrm{H}, \mathrm{H}_{1}, \mathrm{H}_{2}\right), 4.35\left(\mathrm{~d}, J_{\text {gem }}=11.5 \mathrm{~Hz}, 1 \mathrm{H}, \mathrm{OC} \underline{H} \mathrm{HPh}\right)$, $4.38\left(\mathrm{~d}, J_{\text {gem }}=11.5 \mathrm{~Hz}, 1 \mathrm{H}, \mathrm{OC} \underline{H} \mathrm{HPh}\right), 4.41\left(\mathrm{~d}, J_{\text {gem }}=11.5 \mathrm{~Hz}, 1 \mathrm{H}, \mathrm{OC} \underline{H} \mathrm{HPh}\right), 4.51\left(\mathrm{~d}, J_{\text {gem }}=11.5 \mathrm{~Hz}\right.$, 1H, OCㅌH HPh), 7.07-7.12 (m, 2H, Ph), 7.16-7.20 (m, 4H, Ph), 7.21-7.25 (m, 2H, Ph), 7.26-7.27 (m, $2 \mathrm{H}, \mathrm{Ph}) ;{ }^{13} \mathrm{C}-\mathrm{NMR}\left(\mathrm{C}_{6} \mathrm{D}_{6}\right): \delta 14.33\left(\mathrm{CH}_{3}\right), \mathrm{CH}_{2}: 23.08,25.66,29.79,30.03,30.09,30.15,30.28,32.30$; $52.22\left(\mathrm{CH}_{2}, \mathrm{C}_{1}\right), 62.69\left(\mathrm{CH}, \mathrm{C}_{2}\right), 72.20\left(\mathrm{CH}_{2}, \mathrm{OCH}_{2} \mathrm{Ph}\right), 73.75\left(\mathrm{CH}_{2}, \mathrm{OCH}_{2} \mathrm{Ph}\right), 79.05\left(\mathrm{CH}, \mathrm{C}_{4}\right), 79.82$ $\left(\mathrm{CH}, \mathrm{C}_{3}\right), 127.97(\mathrm{CH}, \mathrm{Ph}), 128.07$ (CH, Ph), $128.13(\mathrm{CH}, \mathrm{Ph}), 128.22(\mathrm{CH}, \mathrm{Ph}), 128.29(\mathrm{CH}, \mathrm{Ph}), 128.63$ $(\mathrm{CH}, \mathrm{Ph}), 128.65(\mathrm{CH}, \mathrm{Ph}), 138.30(\mathrm{C}, \mathrm{Ph}), 138.66(\mathrm{C}, \mathrm{Ph})$; LRMS for $\mathrm{C}_{31} \mathrm{H}_{46} \mathrm{~N}_{6} \mathrm{O}_{2}$ : M (calcd.) = 534.3 $(\mathrm{m} / \mathrm{z}), \mathrm{MW}=534.7, \mathrm{ESI}+\mathrm{Q}-\mathrm{TOF}: \mathrm{M}=534.3(\mathrm{~m} / \mathrm{z}),[\mathrm{M}+\mathrm{Na}]^{+}=557.3(100 \%), 558.3(42 \%), 559.3$ (4\%), equivalent to the calculated isotopic ratio; analysis (calcd., found for $\left.\mathrm{C}_{31} \mathrm{H}_{46} \mathrm{~N}_{6} \mathrm{O}_{2}\right)$ : $\mathrm{C}(69.63$, 69.40), H (8.67, 8.53), N (15.72, 15.83).

(2S,3S, 4R)-1-Amino-2-azidoheptadecane-3,4-diol (9): Starting material 8 (38 mg, $0.071 \mathrm{mmol})$ after coevaporation with toluene for three times was dissolved in $\mathrm{CH}_{2} \mathrm{Cl}_{2}(1 \mathrm{~mL})$ under $\mathrm{N}_{2}$. The mixture was cooled down to $-78{ }^{\circ} \mathrm{C} . \mathrm{BCl}_{3} / \mathrm{CH}_{2} \mathrm{Cl}_{2}(1 \mathrm{M}, 35 \mu \mathrm{L}, 0.35 \mathrm{mmol}, 5$ eq. $)$ was added within $2 \mathrm{~min}$. The mixture was stirred at $-78{ }^{\circ} \mathrm{C}$ for $2 \mathrm{~h}$ followed by slow warming to r.t. within 20 min and the stirring was lasted for further $10 \mathrm{~h}$. TLC (EtOAc/n-hexane $=1: 9)$ indicated the consumption of the starting material $8\left(\mathrm{R}_{f}=0.75\right)$ and the formation of the product $9\left(\mathrm{R}_{f}=0.07\right)$. Upon the addition of $\mathrm{MeOH}$ $(0.1 \mathrm{~mL})$, the mixture became an opaque light brown solution. It was then concentrated under reduced pressure to provide a yellow oily residue. The purification of the residue using flash chromatography with $\mathrm{MeOH}-\mathrm{CHCl}_{3}$ 1:9 as eluent and silica gel $(1 \mathrm{~g})$ afforded product 9 in $60 \%$ yield (13 mg). ${ }^{1} \mathrm{H}-\mathrm{NMR}\left(\mathrm{CD}_{3} \mathrm{OD}\right): \delta 0.89$ (t, $J=7.0 \mathrm{~Hz}, 3 \mathrm{H}, \mathrm{H}_{\text {aliphatic }}$ ), 1.24-1.43 (m, 22H, $\mathrm{H}_{\text {aliphatic }}$ ), 1.50-1.62 (m, 
$\left.1 \mathrm{H}, \mathrm{H}_{\text {aliphatic }}\right), 1.68-1.78\left(\mathrm{~m}, 1 \mathrm{H}, \mathrm{H}_{\text {aliphatic }}\right), 3.11\left(\mathrm{dd}, J_{l a, 1 b}=13.0 \mathrm{~Hz}, J_{l a, 2}=8.0 \mathrm{~Hz}, 1 \mathrm{H}, \mathrm{H}_{1 \mathrm{a}}\right), 3.17$ (dd, $\left.J_{l b, 1 a}=13.0, J_{1 b, 2}=3.5 \mathrm{~Hz}, 1 \mathrm{H}, \mathrm{H}_{1 \mathrm{~b}}\right), 3.49\left(\mathrm{td}, J_{2,1 a}=8.0, J_{2,3}=8.0, J_{2,1 b}=3.5 \mathrm{~Hz}, 1 \mathrm{H}, \mathrm{H}_{2}\right), 3.67(\mathrm{dd}$, $\left.J_{3,2}=8.0, J_{3,4}=3.0 \mathrm{~Hz}, 1 \mathrm{H}, \mathrm{H}_{3}\right), 3.92\left(\mathrm{ddd}, J=8.5, J=4.0, J_{4,3}=3.0 \mathrm{~Hz}, 1 \mathrm{H}, \mathrm{H}_{4}\right) ;{ }^{13} \mathrm{C}-\mathrm{NMR}\left(\mathrm{CD}_{3} \mathrm{OD}\right)$ : $\delta 14.43\left(\mathrm{CH}_{3}\right), \mathrm{CH}_{2}: 23.73,26.61,30.47,30.79,33.07,34.89 ; 40.18\left(\mathrm{CH}_{2}, \mathrm{C}_{1}\right), 61.88\left(\mathrm{CH}, \mathrm{C}_{2}\right), 72.92$ $\left(\mathrm{CH}, \mathrm{C}_{4}\right), 76.17\left(\mathrm{CH}, \mathrm{C}_{3}\right)$; LRMS for $\mathrm{C}_{17} \mathrm{H}_{38} \mathrm{~N}_{4} \mathrm{O}_{2}, \mathrm{M}$ (calcd.) $=328.3(\mathrm{~m} / z)$, ESI+Q-TOF: $\mathrm{M}=328.4$ $(\mathrm{m} / \mathrm{z}),[\mathrm{M}+\mathrm{H}]^{+}=329.4(100 \%), 330.4(22 \%)$, equivalent to the calculated isotopic ratio $(100 \%: 18.9 \%)$.

(2S,3S, 4R)-1,2-Diaminoheptadecane-3,4-diol (1): Starting material 8 (812 mg, $1.5 \mathrm{mmol})$ was distilled azeotropically with toluene for three times followed by dissolving in $\mathrm{CH}_{2} \mathrm{Cl}_{2}(20 \mathrm{~mL})$ under $\mathrm{N}_{2}$. The mixture was cooled down to $-78{ }^{\circ} \mathrm{C} . \mathrm{BCl}_{3}\left(15 \mathrm{~mL}, 15 \mathrm{mmol}, 1 \mathrm{M}\right.$ in $\mathrm{CH}_{2} \mathrm{Cl}_{2}, 10$ eq.) was added within $3 \mathrm{~min}$. The mixture was stirred at $-78{ }^{\circ} \mathrm{C}$ for $2 \mathrm{~h}$, followed by warming to $\mathrm{rt}$ within $20 \mathrm{~min}$ and the stirring was lasted for further $10 \mathrm{~h}$. TLC $\left(\mathrm{MeOH} / \mathrm{CHCl}_{3}=2: 8\right)$ indicated the consumption of the starting material $8\left(\mathrm{R}_{f}=0.88\right)$ and the formation of the product $1\left(\mathrm{R}_{f}=0.05\right)$. Upon the addition of $\mathrm{MeOH}(5 \mathrm{~mL})$, the pale yellow solution became a milky white mixture. It was then concentrated under reduced pressure to provide a pale yellow solid. After recrystallization from hot $\mathrm{CHCl}_{3}$, the amorphous precipitate was washed with cold $n$-hexane and dried under reduced pressure to provide the yellow solid 1 in quantitative yield (445 mg). The chemical shifts of protons from $\mathrm{C}_{1}$ to $\mathrm{C}_{4}$ in the ${ }^{1} \mathrm{H}-\mathrm{NMR}$ were slightly upfield. Interestingly, the two ammonium protons were no longer observable between 8 and $9 \mathrm{ppm}$, indicating the presence of a neutral amine rather than the ammonium ion. The protons of the ammonium complex with $\mathrm{HCl}$ could be observed in ${ }^{1} \mathrm{H}-\mathrm{NMR}$. By contrast, no peaks could be found in ESI-MS. $\mathrm{HCl}$ is easier to evaporate during the electrospraying step and thereby only the neutral amino form emerged as the base peak, $303.4(\mathrm{~m} / \mathrm{z})$. In contrast, a substantial amount of the ammonium hydroxide form would be preserved during ESI thereby appearing as the base peak. The patterns of peak clustering around $389.3(\mathrm{~m} / \mathrm{z})$ implied the presence of a chloro-containing molecular ion. mp: $96-100{ }^{\circ} \mathrm{C},{ }^{1} \mathrm{H}-\mathrm{NMR}\left(\mathrm{CD}_{3} \mathrm{OD}\right): \delta 0.88$ (t, $J=7.0 \mathrm{~Hz}, 3 \mathrm{H}, \mathrm{H}_{\text {aliphatic }}$ ), 1.20-1.47 (m, 22H, $\left.\mathrm{H}_{\text {aliphatic }}\right), 1.49-1.62\left(\mathrm{~m}, 1 \mathrm{H}, \mathrm{H}_{\text {aliphatic }}\right), 1.64-1.77\left(\mathrm{~m}, 1 \mathrm{H}, \mathrm{H}_{\text {aliphatic }}\right), 3.30$ (dd, $J_{1 a, 1 b}=14.5, J_{1 a, 2}=4.0 \mathrm{~Hz}$, $\left.1 \mathrm{H}, \mathrm{H}_{1 \mathrm{a}}\right), 3.49\left(\mathrm{dd}, J_{l b, l a}=14.5, J_{l b, 2}=5.0 \mathrm{~Hz}, 1 \mathrm{H}, \mathrm{H}_{1 \mathrm{~b}}\right), 3.66\left(\mathrm{ddd}, J_{4,5 a}=8.0, J_{4,5 b}=8.0, J_{4,3}=3.0 \mathrm{~Hz}\right.$, $\left.1 \mathrm{H}, \mathrm{H}_{4}\right), 3.77\left(\mathrm{dd}, J_{3,2}=7.0, J_{3,4}=3.0 \mathrm{~Hz}, 1 \mathrm{H}, \mathrm{H}_{3}\right), 3.83\left(\mathrm{ddd}, J_{2,3}=7.0, J_{2,1 b}=5.0, J_{2,1 a}=4.0 \mathrm{~Hz}, 1 \mathrm{H}\right.$, $\left.\mathrm{H}_{2}\right), 8.26$ (bs, $\left.1 \mathrm{H}, \mathrm{NH}\right), 8.47$ (bs, $\left.1 \mathrm{H}, \mathrm{NH}\right) ;{ }^{13} \mathrm{C}-\mathrm{NMR}\left(\mathrm{CD}_{3} \mathrm{OD}\right): \delta 14.44\left(\mathrm{CH}_{3}\right), \mathrm{CH}_{2}: 23.69,26.57$, 30.44, 30.73, 30.76, 33.03, 34.76; $39.15\left(\mathrm{CH}_{2}, \mathrm{C}_{1}\right), 51.87\left(\mathrm{CH}, \mathrm{C}_{2}\right), 73.76\left(\mathrm{CH}, \mathrm{C}_{4}\right), 74.01\left(\mathrm{CH}, \mathrm{C}_{3}\right)$; LRMS for $\mathrm{C}_{17} \mathrm{H}_{38} \mathrm{~N}_{2} \mathrm{O}_{2}: \mathrm{M}=302.3$ (calcd.); $\mathrm{ESI}+\mathrm{Q}-\mathrm{TOF}: \mathrm{M}=302.4(\mathrm{~m} / \mathrm{z}),[\mathrm{M}+\mathrm{H}]^{+}=303.4(100 \%)$, $304.4(20 \%)$, equivalent to the calculated isotopic ratio; $[\mathrm{M}+\mathrm{Na}]^{+}=325.3,[2 \mathrm{M}+\mathrm{H}]^{+}=605.6$. A sample was further purified with anionic ion exchange resin $\left(\mathrm{OH}^{-}\right)$. Following the gentle stirring of the mixture in $\mathrm{MeOH}$ for $2 \mathrm{~min}$, it was filtered by paper. The filtrate collected was concentrated to provide white solid for subsequent analysis with ${ }^{1} \mathrm{H}-\mathrm{NMR}$ and ESI-MS. ${ }^{1} \mathrm{H}-\mathrm{NMR}\left(\mathrm{CD}_{3} \mathrm{OD}\right): \delta 0.89(\mathrm{t}, J=7.0 \mathrm{~Hz}$, $\left.3 \mathrm{H}, \mathrm{H}_{\text {aliphatic }}\right), 1.20-1.41$ (m, 24H, $\left.\mathrm{H}_{\text {aliphatic }}\right), 1.45-1.65$ (m, $\left.1 \mathrm{H}, \mathrm{H}_{\text {aliphatic }}\right), 1.70-1.76\left(\mathrm{~m}, 1 \mathrm{H}, \mathrm{H}_{\text {aliphatic }}\right)$, 2.69 (bs, 1H), 2.89 (bs, 2H), 3.30 (bs, $1 \mathrm{H}), 3.45-3.52 \mathrm{~m}, 1 \mathrm{H}), 3.77\left(\mathrm{dd}, J_{3,2}=7.0, J_{3,4}=3.0 \mathrm{~Hz}, 1 \mathrm{H}\right.$, $\mathrm{H}_{3}$ ); LRMS for $\mathrm{C}_{17} \mathrm{H}_{38} \mathrm{~N}_{2} \mathrm{O}_{2}$ : ESI+Q-TOF: $\mathrm{M}=302.4(\mathrm{~m} / \mathrm{z}),[\mathrm{M}+\mathrm{H}]^{+}=303.4(25 \%), 304.4(5 \%)$, $\left[\mathrm{M}+\mathrm{H}_{2} \mathrm{O}+\mathrm{Na}\right]^{+}=343.4(100 \%), 344.4(29 \%), 345.4(4)$, roughly equivalent to the calculated isotopic ratio (100:18.4:1.6); $\left[\mathrm{M}+2 \mathrm{H}_{2} \mathrm{O}+\mathrm{K}\right]^{+}=377.4$. 
2-Azido-3,4-di-O-benzyl-1-O-(6-azido-2,3,4-tri-O-benzyl- $\alpha$-D-galactopyranosyl)-D-ribo-heptadecan-1ol $(\mathbf{1 4 \alpha})$ : To a solution of donor 10 (954 mg, $1.64 \mathrm{mmol})$ and acceptor 4 (601 $\mathrm{mg}, 1.12 \mathrm{mmol})$ in $\mathrm{CH}_{2} \mathrm{Cl}_{2}(10 \mathrm{~mL})$ under $\mathrm{N}_{2} 4 \AA$ molecular sieve $(1.8 \mathrm{~g})$ was added. The stirring at $\mathrm{rt}$ was continued for $30 \mathrm{~min}$, followed by cooling down to $0{ }^{\circ} \mathrm{C}$. To the mixture was then added $N$-iodosuccinimide $(1.56 \mathrm{~g}$, $7.0 \mathrm{mmol})$ and TfOH (13 mg, $0.09 \mathrm{mmol})$, prepared by dissolving TfOH $(0.5 \mathrm{~mL})$ in $\mathrm{CH}_{2} \mathrm{Cl}_{2}(10 \mathrm{~mL})$. The stirring was lasted for $30 \mathrm{~min}$. TLC (EtOAc $/ n$-hexane $=1: 9)$ indicated the consumption of the acceptor $4\left(\mathrm{R}_{f}=0.22\right)$ and the formation of the product $14 \alpha\left(\mathrm{R}_{f}=0.50\right)$ and product $14 \beta\left(\mathrm{R}_{f}=0.34\right)$. When adding $\mathrm{CH}_{2} \mathrm{Cl}_{2}(20 \mathrm{~mL})$ and saturated aqueous $\mathrm{Na}_{2} \mathrm{~S}_{2} \mathrm{O}_{3}(20 \mathrm{~mL})$ for partition, the solution turned from dark violet to white. The organic layer was further extracted with saturated aqueous $\mathrm{NaHCO}_{3}(20 \mathrm{~mL})$. After drying the organic layer with $\mathrm{Na}_{2} \mathrm{SO}_{4}$, the solution was filtered through celite pad and concentrated under reduced pressure. The residue obtained was purified by flash chromatography with EtOAc/ $n$-hexane $=1: 19$ as eluent to provide compound $14 \alpha$ in $51 \%$ yield $(583 \mathrm{mg}$ ) and compound $14 \beta$ in $44 \%$ yield $(501 \mathrm{mg})$, both of oily appearance. ${ }^{1} \mathrm{H}-\mathrm{NMR}\left(\mathrm{C}_{6} \mathrm{D}_{6}\right): \delta 0.91(\mathrm{t}, 3 \mathrm{H}$, $\left.\mathrm{CH}_{3}\right), 1.22-1.36\left(\mathrm{~m}, 20 \mathrm{H}, \mathrm{CH}_{2}\right), 1.32-1.48$ (m, 1H, $\left.\mathrm{C} \underline{H}\right), 1.50-1.58(\mathrm{~m}, 1 \mathrm{H}, \mathrm{C} \underline{H} \mathrm{H}), 1.58-166(\mathrm{~m}, 1 \mathrm{H}$, CㅂH), $1.84-1.91(\mathrm{~m}, 1 \mathrm{H}, \mathrm{C} \underline{H} \mathrm{H}), 2.74\left(\mathrm{dd}, J_{6^{\prime} a, \sigma^{\prime} b}=12.5, J_{6^{\prime} a, 5}=4.0 \mathrm{~Hz}, 1 \mathrm{H}, \mathrm{H}-66^{\prime} \mathrm{a}\right), 3.45(\mathrm{~s}, 1 \mathrm{H}$, H-4'), 3.47 (dd, $\left.J_{6^{\prime} b, 6^{\prime} a}=12.5, J_{6^{\prime}, 5}{ }^{\prime}=8.0 \mathrm{~Hz}, 1 \mathrm{H}, \mathrm{H}-6^{\prime} \mathrm{b}\right), 3.72-3.78\left(\mathrm{~m}, 3 \mathrm{H}, \mathrm{H}_{1 \mathrm{a}}, \mathrm{H}_{2}, \mathrm{H}_{4}\right), 3.82$ (dd, $\left.J_{5^{\prime}, 6 \mathrm{~b}}=8.0, J_{5^{\prime}, 6 \mathrm{a}}=4.0 \mathrm{~Hz}, 1 \mathrm{H}, \mathrm{H}_{5^{\prime}}\right), 3.87\left(\mathrm{t}, J=4.3 \mathrm{~Hz}, 1 \mathrm{H}, \mathrm{H}_{3}\right), 4.04\left(\mathrm{dd}, J_{2^{\prime}, 3^{\prime}}=10.5, J_{2^{\prime}, 1^{\prime}}=3.5 \mathrm{~Hz}\right.$, $\left.1 \mathrm{H}, \mathrm{H}_{2^{\prime}}\right), 4.16\left(\mathrm{dd}, J_{3^{\prime}, 2^{\prime}}=10.5, J_{3^{\prime} 4^{\prime}}=4.0 \mathrm{~Hz}, 1 \mathrm{H}, \mathrm{H}_{3^{\prime}}\right), 4.20\left(\mathrm{dd}, J_{1 b, 1 a}=13.0, J_{1 b, 2}=6.0 \mathrm{~Hz}, 1 \mathrm{H}, \mathrm{H}_{1 \mathrm{~b}}\right)$, 4.42-4.48 (m, 3H, $\left.\underline{\mathrm{H}}_{2} \mathrm{Ph}\right), 4.57-4.64\left(\mathrm{~m}, 4 \mathrm{H}, \underline{\mathrm{C}}_{2} \mathrm{Ph}\right), 4.71\left(\mathrm{~d}, J=11.5 \mathrm{~Hz}, 1 \mathrm{H}, \underline{\mathrm{C}}_{2} \mathrm{Ph}\right), 4.78(\mathrm{~d}$, $\left.J=11.5 \mathrm{~Hz}, 1 \mathrm{H}, \mathrm{C}_{2} \mathrm{Ph}\right), 4.88\left(\mathrm{~d}, J_{1^{\prime}, 2^{\prime}}=3.5 \mathrm{~Hz}, 1 \mathrm{H}, \mathrm{H}_{1^{\prime}}\right), 4.98(\mathrm{~d}, J=11.5,1 \mathrm{H}, \mathrm{C} \underline{\mathrm{H}} 2 \mathrm{Ph}), 7.00-7.05$ (m, 1H, $\left.\mathrm{H}_{\mathrm{Bn}}\right), 7.08-7.12\left(\mathrm{~m}, 6 \mathrm{H}, \mathrm{H}_{\mathrm{Bn}}\right), 7.16-7.21\left(\mathrm{~m}, 8 \mathrm{H}, \mathrm{H}_{\mathrm{Bn}}\right), 7.28-7.30\left(\mathrm{~m}, 4 \mathrm{H}, \mathrm{H}_{\mathrm{Bn}}\right), 7.31-7.33$ (m, $\left.2 \mathrm{H}, \mathrm{H}_{\mathrm{Bn}}\right), 7.34-7.37\left(\mathrm{~m}, 4 \mathrm{H}, \mathrm{H}_{\mathrm{Bn}}\right) ;{ }^{13} \mathrm{C}-\mathrm{NMR}\left(\mathrm{C}_{6} \mathrm{D}_{6}\right): \delta 14.33\left(\mathrm{CH}_{3}\right), \mathrm{CH}_{2}: 23.08,26.01,29.79,30.15$, 30.22, 30.35, 32.30, 51.84; $62.43(\mathrm{CH}), 68.69\left(\mathrm{CH}_{2}\right), 70.91(\mathrm{CH}), 72.26\left(\underline{\mathrm{CH}}_{2} \mathrm{Ph}\right), 73.36\left(\underline{\mathrm{CH}}_{2} \mathrm{Ph}\right)$, $73.62\left(\underline{\mathrm{CH}}_{2} \mathrm{Ph}\right), 74.01\left(\underline{\mathrm{CH}}_{2} \mathrm{Ph}\right), 75.04\left(\underline{\mathrm{CH}}_{2} \mathrm{Ph}\right), 76.22(\mathrm{CH}), 77.08(\mathrm{CH}), 78.88(\mathrm{CH}), 79.09(\mathrm{CH})$, $79.98(\mathrm{CH}), 98.75(\mathrm{CH}), 127.66(\mathrm{CH}, \mathrm{Ph}), 127.80(\mathrm{CH}, \mathrm{Ph}), 128.00(\mathrm{CH}, \mathrm{Ph}), 128.19(\mathrm{CH}, \mathrm{Ph}), 128.29$ (CH, Ph), 128.44 (CH, Ph), 128.49 (CH, Ph), 128.57 (CH, Ph), 128.62 (CH, Ph), 138.85 (C, Ph), 138.99 (C, Ph), $139.15(\mathrm{C}, \mathrm{Ph}), 139.19(\mathrm{C}, \mathrm{Ph}), 139.30(\mathrm{C}, \mathrm{Ph})$; LRMS for $\mathrm{C}_{58} \mathrm{H}_{74} \mathrm{~N}_{6} \mathrm{O}_{7}: \mathrm{M}$ (calcd.) = 966.6 $(\mathrm{m} / \mathrm{z}), \mathrm{ESI}+\mathrm{Q}-\mathrm{TOF}: \mathrm{M}=966.6(\mathrm{~m} / \mathrm{z}),[\mathrm{M}-\mathrm{H}+\mathrm{H}]^{+}=966.6, \mathrm{M}^{\prime}=\mathrm{M}-\mathrm{H}^{+}+\mathrm{NH}_{4}^{+},\left[2 \mathrm{M}^{\prime}+\mathrm{H}\right]^{+}=1967.0$; analysis (calcd., found for $\left.\mathrm{C}_{58} \mathrm{H}_{74} \mathrm{~N}_{6} \mathrm{O}_{7}\right)$ : $\mathrm{C}(72.02,72.11), \mathrm{H}(7.71,7.42), \mathrm{N}(8.69,8.66)$.

2-Azido-3,4-di-O-benzyl-1-O-(6-azido-2,3,4-tri-O-benzyl- $\beta$-D-galactopyranosyl)-D-ribo-heptadecan-1ol (14及): ${ }^{1} \mathrm{H}-\mathrm{NMR}\left(\mathrm{C}_{6} \mathrm{D}_{6}\right): \delta 0.91\left(\mathrm{t}, 3 \mathrm{H}, \mathrm{CH}_{3}\right), 1.19-1.35\left(\mathrm{~m}, 20 \mathrm{H}, \mathrm{CH}_{2}\right), 1.36-1.46(\mathrm{~m}, 1 \mathrm{H}, \mathrm{CH})$,

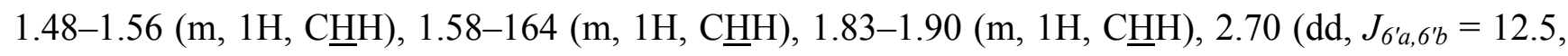
$\left.J_{6^{\prime}, 5}=4.0 \mathrm{~Hz}, 1 \mathrm{H}, \mathrm{H}_{6^{\prime}}\right), 2.94\left(\mathrm{dd}, J_{3,2}=7.5, J_{3,4}=4.0 \mathrm{~Hz}, 1 \mathrm{H}, \mathrm{H}_{3}\right), 3.22\left(\mathrm{dd}, J_{3^{\prime}, 2^{\prime}}=9.5 \mathrm{~Hz}, J_{3^{\prime}, 4^{\prime}}=3.0 \mathrm{~Hz}\right.$, $\left.1 \mathrm{H}, \mathrm{H}_{3^{\prime}}\right), 3.28\left(\mathrm{dd}, J_{4^{\prime}, 3^{\prime}}=3.0, J_{4^{\prime}, 5^{\prime}}=2.5 \mathrm{~Hz}, 1 \mathrm{H}, \mathrm{H}_{4^{\prime}}\right), 3.38\left(\mathrm{dd}, J_{6^{\prime} b, 6^{\prime} a}=12.5, J_{6^{\prime} b, 5^{\prime}}=7.5 \mathrm{~Hz}, 1 \mathrm{H}, \mathrm{H}_{6^{\prime} \mathrm{b}}\right)$, $3.73\left(\mathrm{ddd}, J_{2,3}=7.5, J_{2,1 a}=3.0, J_{2,1 b}=2.5 \mathrm{~Hz}, 1 \mathrm{H}, \mathrm{H}_{2}\right), 3.80\left(\mathrm{ddd}, J_{5^{\prime}, 6 b^{\prime}}=7.5, J_{5^{\prime}, 6 a^{\prime}}=4.0, J_{5^{\prime} 4^{\prime}}=2.5\right.$ $\left.\mathrm{Hz}, 1 \mathrm{H}, \mathrm{H}_{5^{\prime}}\right), 3.82-3.86\left(\mathrm{~m}, 1 \mathrm{H}, \mathrm{H}_{4}\right), 3.94\left(\mathrm{dd}, J_{1 a, l b}=10.5, J_{1 a, 2}=2.5 \mathrm{~Hz}, 1 \mathrm{H}, \mathrm{H}_{1 \mathrm{a}}\right), 4.06\left(\mathrm{dd}, J_{2^{\prime}, 3^{\prime}}=\right.$ $\left.9.5, J_{2^{\prime} l^{\prime}}=7.5 \mathrm{~Hz}, 1 \mathrm{H}, \mathrm{H}_{2^{\prime}}\right), 4.26\left(\mathrm{~d}, J_{1^{\prime}, 2^{\prime}}=7.5 \mathrm{~Hz}, 1 \mathrm{H}, \mathrm{H}_{1^{\prime}}\right), 4.39\left(\mathrm{dd}, J_{1 b, 1 a}=10.5, J_{1 b, 2}=6.5 \mathrm{~Hz}, 1 \mathrm{H}\right.$, $\left.\mathrm{H}_{1 \mathrm{~b}}\right), 4.42\left(\mathrm{dd}, J=12.0 \mathrm{~Hz}, 1 \mathrm{H}, \underline{\mathrm{C}}_{2} \mathrm{Ph}\right), 4.44\left(\mathrm{dd}, J=12.0 \mathrm{~Hz}, 1 \mathrm{H}, \underline{\mathrm{C}}_{2} \mathrm{Ph}\right), 4.53$ (dd, $J=12.0 \mathrm{~Hz}$, $\left.1 \mathrm{H}, \underline{\mathrm{C}}_{2} \mathrm{Ph}\right), 4.55\left(\mathrm{dd}, J=11.5 \mathrm{~Hz}, 1 \mathrm{H}, \underline{\mathrm{C}}_{2} \mathrm{Ph}\right), 4.64-4.70(\mathrm{~m}, 3 \mathrm{H}), 4.76\left(\mathrm{~d}, J=11.0 \mathrm{~Hz}, 1 \mathrm{H}, \underline{\mathrm{C}}_{2} \mathrm{Ph}\right)$, $4.94\left(\mathrm{~d}, J=11.5 \mathrm{~Hz}, 1 \mathrm{H}, \mathrm{C}_{2} \mathrm{Ph}\right), 5.09$ (d, $\left.J=11.5 \mathrm{~Hz}, 1 \mathrm{H}, \mathrm{C}_{2} \mathrm{Ph}\right), 7.07-7.13\left(\mathrm{~m}, 7 \mathrm{H}, \mathrm{H}_{\mathrm{Bn}}\right), 7.16-$ $7.21\left(\mathrm{~m}, 8 \mathrm{H}, \mathrm{H}_{\mathrm{Bn}}\right), 7.25-7.26\left(\mathrm{~m}, 2 \mathrm{H}, \mathrm{H}_{\mathrm{Bn}}\right), 7.32-7.34\left(\mathrm{~m}, 4 \mathrm{H}, \mathrm{H}_{\mathrm{Bn}}\right), 7.36-7.37\left(\mathrm{~m}, 2 \mathrm{H}, \mathrm{H}_{\mathrm{Bn}}\right), 7.45-$ 
$7.46\left(\mathrm{~m}, 2 \mathrm{H}, \mathrm{H}_{\mathrm{Bn}}\right) ;{ }^{13} \mathrm{C}-\mathrm{NMR}\left(\mathrm{C}_{6} \mathrm{D}_{6}\right): \delta 14.33\left(\mathrm{CH}_{3}\right), \mathrm{CH}_{2}: 23.08,25.95,29.79,30.11,30.15,30.22$, 30.30, 32.30, 51.40; $62.64(\mathrm{CH}), 69.15\left(\mathrm{CH}_{2}\right), 72.12\left(\underline{\mathrm{CH}}_{2} \mathrm{Ph}\right), 73.42\left(\underline{\mathrm{CH}}_{2} \mathrm{Ph}\right), 73.86\left(\underline{\mathrm{CH}}_{2} \mathrm{Ph}\right), 74.20$ $(\mathrm{CH}), 74.75(\mathrm{CH}), 74.89\left(\underline{\mathrm{CH}}_{2} \mathrm{Ph}\right), 75.29\left(\underline{\mathrm{CH}}_{2} \mathrm{Ph}\right), 78.93(\mathrm{CH}), 79.82(\mathrm{CH}), 82.01(\mathrm{CH}), 104.08(\mathrm{CH})$, $127.61(\mathrm{CH}, \mathrm{Ph}), 127.70(\mathrm{CH}, \mathrm{Ph}), 127.81(\mathrm{CH}, \mathrm{Ph}), 127.92(\mathrm{CH}, \mathrm{Ph}), 128.00(\mathrm{CH}, \mathrm{Ph}), 128.19(\mathrm{CH}$, $\mathrm{Ph}), 128.29$ (CH, Ph), $128.38(\mathrm{CH}, \mathrm{Ph}), 128.45$ (CH, Ph), $128.57(\mathrm{CH}, \mathrm{Ph}), 128.65$ (CH, Ph), 138.82 (C, Ph), 139.07 (C, Ph), 139.13 (C, Ph), 139.59 (C, Ph).

2-Azido-3,4-di-O-benzoyl-1-O-(6-azido-2,3,4-tri-O-benzyl- $\alpha$-D-galactopyranosyl)-D-ribo-octadecan-1ol $(\mathbf{1 5 \alpha}, \boldsymbol{\beta})$ : A mixture of donor $10(50 \mathrm{mg}, 0.86 \mathrm{mmol})$ and acceptor 12 (79 mg, $0.14 \mathrm{mmol}, 1.5$ eq.) was azeotropically distilled with toluene $(10 \mathrm{~mL})$ for three times. $\mathrm{CH}_{2} \mathrm{Cl}_{2}(1.5 \mathrm{~mL})$ and powdered $4 \AA$ MS (150 mg) were added, sequentially, under $\mathrm{N}_{2}$. After stirring for $30 \mathrm{~min}$, the mixture was moved to an ice bath. Following the addition of NIS (126 mg, $0.56 \mathrm{mmol}, 6.2$ eq.), the flask was stirred at $-78{ }^{\circ} \mathrm{C}$ for $5 \mathrm{~min}$. TfOH $(0.56 \mu \mathrm{L}, 0.006 \mathrm{mmol}, 0.1 \mathrm{eq}$. $)$ was added, while the mixture turned dark red. The stirring was warmed to $-20{ }^{\circ} \mathrm{C}$ during $10 \mathrm{~min}$. After $1 \mathrm{~h}$, TLC (EtOAc/ $n$-hexane $=1: 9$ ) indicated the formation of the products $15 \alpha, \beta\left(\mathrm{R}_{f}=0.66\right)$ and the consumption of the acceptor $12\left(\mathrm{R}_{f}=0.26\right)$ and the donor $10\left(\mathrm{R}_{f}=0.66\right)$. The mixture were filtered through a Celite pad and the filtrate obtained was concentrated under reduced pressure. The residue was dissolved in EtOAc and treated with $\mathrm{Na}_{2} \mathrm{~S}_{2} \mathrm{O}_{3(\mathrm{aq})}$ $(3 \mathrm{~mL})$, followed by extraction with $\mathrm{NaHCO}_{3(\mathrm{aq})}(5 \mathrm{~mL})$. The organic phase was collected and dried with $\mathrm{Na}_{2} \mathrm{SO}_{4}$, followed by filtration with a Celite pad. The filtrate was concentrated under reduced pressure and the resultant residue was purified by flash chromatography using eluents of EtOAc/ $n$-hexane $=1: 39$ to provide the colorless product mixtures 15 in $65 \%$ yield $(60 \mathrm{mg})$ and $\alpha: \beta$ ratio of $2: 1$. Each of the two anomers could be collected in its pure form from the fractions. Data of 15 $\alpha$ : ${ }^{1} \mathrm{H}-\mathrm{NMR}\left(\mathrm{CDCl}_{3}\right): \delta 0.86\left(\mathrm{t}, J=7.0 \mathrm{~Hz}, 3 \mathrm{H}, \mathrm{H}_{\text {aliphatic }}\right), 1.19-1.40$ (m, 24H, $\left.\mathrm{H}_{\text {aliphatic }}\right), 1.83-1.85$ (m, $\left.2 \mathrm{H}, \mathrm{H}_{\text {aliphatic }}\right), 2.91\left(\mathrm{dd}, J_{6 \mathrm{a}^{\prime}, 6 \mathrm{~b}^{\prime}}=12.5 \mathrm{~Hz}, J_{6 \mathrm{a}^{\prime}, 5^{\prime}}=5.0 \mathrm{~Hz}, 1 \mathrm{H}, \mathrm{H}-6 \mathrm{a}^{\prime}\right), 3.43\left(\mathrm{dd}, J_{6 \mathrm{~b}^{\prime}, 6 \mathrm{a}^{\prime}}=12.5\right.$, $\left.J_{6 \mathrm{~b}^{\prime}, 5^{\prime}}=8.5 \mathrm{~Hz}, 1 \mathrm{H}, \mathrm{H}-6 \mathrm{~b}^{\prime}\right), 3.68\left(\mathrm{dd}, J_{1 \mathrm{a}, 1 \mathrm{~b}}=10.5, J_{1 \mathrm{a}, 2}=7.5 \mathrm{~Hz}, 1 \mathrm{H}, \mathrm{H}-1 \mathrm{a}\right), 3.73$ (bs, 1H, H-4'), 3.82 (dd, $\left.J_{5^{\prime}, 6 \mathrm{~b}^{\prime}}=8.5, J_{5^{\prime}, 6 \mathrm{a}^{\prime}}=5.0 \mathrm{~Hz}, 1 \mathrm{H}, \mathrm{H}-5^{\prime}\right), 3.90\left(\mathrm{dd}, J_{3^{\prime}, 2^{\prime}}=10.0, J_{3^{\prime}, 4^{\prime}}=3.0 \mathrm{~Hz}, 1 \mathrm{H}, \mathrm{H}-3^{\prime}\right), 3.98(\mathrm{dd}$, $\left.J_{2^{\prime}, 3^{\prime}}=10.0, J_{2^{\prime}, 1^{\prime}}=4.0 \mathrm{~Hz}, 1 \mathrm{H}, \mathrm{H}-2^{\prime}\right), 4.00\left(\mathrm{dd}, J_{2,1 \mathrm{a}}=7.5, J_{2,1 \mathrm{~b}}=3.0 \mathrm{~Hz}, 1 \mathrm{H}, \mathrm{H}-2\right), 4.03\left(\mathrm{dd}, J_{1 \mathrm{~b}, 1 \mathrm{a}}=10.5\right.$, $\left.J_{1 \mathrm{~b}, 2}=3.0 \mathrm{~Hz}, 1 \mathrm{H}, \mathrm{H}-1 \mathrm{~b}\right), 4.55\left(\mathrm{~d}, 1 \mathrm{H}, J=11.5 \mathrm{~Hz}, \mathrm{C}_{2} \mathrm{Ph}\right), 4.62\left(\mathrm{~d}, 1 \mathrm{H}, J=12.5 \mathrm{~Hz}, \mathrm{C}_{2} \mathrm{Ph}\right)$, $4.67-4.70\left(\mathrm{~d}, J=11.5 \mathrm{~Hz}, 2 \mathrm{H}, \mathrm{C}_{2} \mathrm{Ph}\right), 4.80\left(\mathrm{~d}, 1 \mathrm{H}, J_{1^{\prime}, 2^{\prime}}=4.0 \mathrm{~Hz}, \mathrm{H}_{1^{\prime}}\right), 4.83(\mathrm{~d}, 1 \mathrm{H}, J=11.5 \mathrm{~Hz}$, $\left.\mathrm{C}_{2} \mathrm{Ph}\right), 4.95\left(\mathrm{~d}, 1 \mathrm{H}, J=11.5 \mathrm{~Hz}, \underline{\mathrm{CH}}_{2} \mathrm{Ph}\right), 5.50-5.53$ (m, 2H, H-3+H-4), 7.14-7.44 (m, 19H, ArH), 7.52-7.86 (m, 2H, ArH), 7.96-8.01 (m, 4H, ArH); ${ }^{13} \mathrm{C}-\mathrm{NMR}\left(\mathrm{CDCl}_{3}\right): \delta 14.11\left(\mathrm{CH}_{3}\right), \mathrm{CH}_{2}: 22.68$, 25.31, 29.35, 29.38, 29.41, 29.50, 29.58, 29.64, 29.67, 29.69, 29.87, 31.92, 51.40; 61.36 (CH), 68.54 $\left(\mathrm{CH}_{2}\right), 70.32(\mathrm{CH}), 72.86(\mathrm{CH}), 72.90(\mathrm{CH}), 73.12\left(\mathrm{CH}_{2}, \underline{\mathrm{CH}}_{2} \mathrm{Ph}\right), 73.65\left(\mathrm{CH}_{2}, \underline{\mathrm{CH}}_{2} \mathrm{Ph}\right), 74.58\left(\mathrm{CH}_{2}\right.$, $\left.\mathrm{C}_{2} \mathrm{Ph}\right), 75.20(\mathrm{CH}), 76.21(\mathrm{CH}), 78.42(\mathrm{CH}), 98.80(\mathrm{CH})$; arom. $\mathrm{CH}: 127.55,127.59,127.83,127.89$, $128.27,128.38,128.43,128.47,128.56,129.73,129.87,133.16,133.48$; arom. quaternary $\mathrm{C}: 129.32$, 129.79, 138.10, 138.51, 138.70; $165.15(\mathrm{CO}), 165.73(\mathrm{CO})$. Data of $\mathbf{1 5 \beta}:{ }^{1} \mathrm{H}-\mathrm{NMR}\left(\mathrm{CDCl}_{3}\right): \delta 0.86(\mathrm{t}$, $\left.3 \mathrm{H}, J=7.0 \mathrm{~Hz}, \mathrm{H}_{\text {aliphatic }}\right), 1.16-1.43$ (m, 22H, $\left.\mathrm{H}_{\text {aliphatic }}\right), 1.57$ (bs, 2H, $\left.\mathrm{H}_{\text {aliphatic }}\right), 1.78-1.86$ (m, 2H, $\mathrm{H}_{\text {aliphatic }}$ ), $2.82\left(\mathrm{dd}, J_{6 \mathrm{a}^{\prime}, 6 \mathrm{~b}^{\prime}}=12.0 \mathrm{~Hz}, J_{6 \mathrm{a}^{\prime}, 5^{\prime}}=4.5 \mathrm{~Hz}, 1 \mathrm{H}, \mathrm{H}_{6 \mathrm{a}^{\prime}}\right), 3.39\left(\mathrm{dd}, J_{6 \mathrm{~b}^{\prime}, 6 \mathrm{a}^{\prime}}=12.0, J_{6 \mathrm{~b}^{\prime}, 5^{\prime}}=7.5 \mathrm{~Hz}, 1 \mathrm{H}, \mathrm{H}-6 \mathrm{~b}^{\prime}\right)$, $3.43\left(\mathrm{dd}, J_{5^{\prime}, 6 \mathrm{~b}^{\prime}}=7.5, J_{5^{\prime}, 6 \mathrm{a}^{\prime}}=4.5 \mathrm{~Hz}, 1 \mathrm{H}, \mathrm{H}-5^{\prime}\right), 3.47\left(\mathrm{dd}, J_{3^{\prime}, 2^{\prime}}=9.5, J_{3^{\prime}, 4^{\prime}}=2.5 \mathrm{~Hz}, 1 \mathrm{H}, \mathrm{H}-3^{\prime}\right), 3.65(\mathrm{~d}$, $\left.J=1.0 \mathrm{~Hz}, 1 \mathrm{H}, \mathrm{H}-4^{\prime}\right), 3.83\left(\mathrm{dd}, J_{2^{\prime}, 3^{\prime}}=9.5, J_{2^{\prime}, 1^{\prime}}=8.0 \mathrm{~Hz}, 1 \mathrm{H}, \mathrm{H}-2^{\prime}\right), 3.90\left(\mathrm{dd}, J_{1 \mathrm{a}, 1 \mathrm{~b}}=10.5, J_{1 \mathrm{a}, 2}=1.5 \mathrm{~Hz}\right.$, $1 \mathrm{H}, \mathrm{H}-1 \mathrm{a}), 3.96$ (bs, $1 \mathrm{H}, \mathrm{H}-2), 4.14$ (dd, $\left.J_{1 \mathrm{~b}, 1 \mathrm{a}}=10.5, J_{1 \mathrm{~b}, 2}=8.5 \mathrm{~Hz}, 1 \mathrm{H}, \mathrm{H}-1 \mathrm{~b}\right), 4.36$ (d, $J_{1^{\prime}, 2^{\prime}}=8.0 \mathrm{~Hz}$, $\left.1 \mathrm{H}, \mathrm{H}_{1}{ }^{\prime}\right), 4.58\left(\mathrm{~d}, J=11.5 \mathrm{~Hz}, 1 \mathrm{H}, \mathrm{CH}_{2} \mathrm{Ph}\right), 4.70\left(\mathrm{~d}, J=11.5 \mathrm{~Hz}, 1 \mathrm{H}, \mathrm{C}_{2} \mathrm{Ph}\right), 4.73(\mathrm{~d}, J=10.5 \mathrm{~Hz}$, 
$\left.1 \mathrm{H}, \underline{\mathrm{C}}_{2} \mathrm{Ph}\right), 4.77$ ( d, $\left.J=10.5 \mathrm{~Hz}, 1 \mathrm{H}, \underline{\mathrm{C}}_{2} \mathrm{Ph}\right), 4.89$ (d, $\left.1 \mathrm{H}, J=11.0 \mathrm{~Hz}, \mathrm{H}_{1}\right), 4.96$ (d, $1 \mathrm{H}, J=11.5 \mathrm{~Hz}$, $\left.\mathrm{C}_{2} \mathrm{Ph}\right), 5.48-5.54$ (m, 2H, H-3+H-4), 7.20-7.36 (m, 14H, ArH), 7.36-7.43 (m, 5H, ArH), 7.51-7.58 (m, 2H, ArH), 7.96-8.00 (m, 4H, ArH); ${ }^{13} \mathrm{C}-\mathrm{NMR}\left(\mathrm{CDCl}_{3}\right): \delta 14.07\left(\mathrm{CH}_{3}\right), \mathrm{CH}_{2}: 22.67,25.28,29.34$, 29.39, 29.49, 29.57, 29.62, 30.10, 31.90, 51.0; $61.42(\mathrm{CH}), 68.50\left(\mathrm{CH}_{2}\right), 72.81(\mathrm{CH}), 72.97(\mathrm{CH})$,

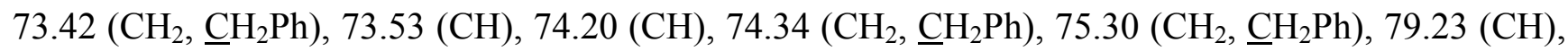
$81.89(\mathrm{CH}), 103.43(\mathrm{CH})$, arom. $\mathrm{CH}: 127.47,127.58,127.71,127.84,127.98,128.22,128.33,128.43$, $128.46,129.74,129.92,133.12,133.34$; arom. quaternary $\mathrm{C}: 129.39,129.78,138.05,138.22,138.63$; $165.05(\mathrm{CO}), 165.71(\mathrm{CO})$; LRMS for $\mathrm{C}_{59} \mathrm{H}_{72} \mathrm{~N}_{6} \mathrm{O}_{9}: \mathrm{M}$ (calcd.) = $1008.5(\mathrm{~m} / \mathrm{z})$, ESI+Q-TOF: $\mathrm{M}=1008.6(\mathrm{~m} / \mathrm{z}),[\mathrm{M}+\mathrm{Na}]^{+}=1031.6(3.67 \%), 1032.6(2.54 \%)$, approximately equivalent to the calculated isotopic ratio (100\%:65\%). Coupling of 11 and 12 afforded only the undesired silylated

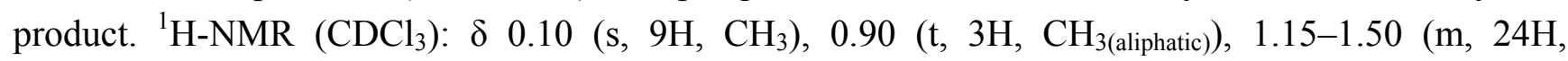
$\mathrm{H}_{\text {aliphatic }}$ ), 1.80-2.00 (m, 2H, $\left.\mathrm{H}_{\text {aliphatic }}\right), 3.75-4.00(\mathrm{~m}, 3 \mathrm{H}), 5.46-5.56\left(\mathrm{~m}, 2 \mathrm{H}, \mathrm{H}_{3}, \mathrm{H}_{4}\right), 7.40-7.50$ (m, 4H, ArH), 7.53-7.63 (m, 2H, ArH), 7.98-8.00 (m, 4H, ArH). Attempt to synthesize compound 16 by coupling 10 and 13. Anal. $\mathrm{C}_{83} \mathrm{H}_{124} \mathrm{~N}_{4} \mathrm{O}_{8}, \mathrm{M}$ (calcd.) $=1304.9(\mathrm{~m} / \mathrm{z})$; ESI+Q-TOF: $\mathrm{M}=1304.8(\mathrm{~m} / \mathrm{z})$, $[\mathrm{M}+\mathrm{Na}]^{+}=1327.8(8.7 \%), 1328.6(7.8 \%), 1329.5(3.6 \%)$, approximately equivalent to the calculated isotopic ratio (100\%:91.5\%:43.0\%).

2-Amino-1-O-(6-amino- $\beta$-D-galactopyranosyl)-D-ribo-heptadecan-1,3,4-ol (17ß): To a solution of $\beta$-anomer $14 \beta$ (40 mg, $0.41 \mathrm{mmol})$ in $\mathrm{CHCl}_{3}(0.5 \mathrm{~mL})$ was added $\mathrm{MeOH}(2 \mathrm{~mL})$. AcOH $(20 \mu \mathrm{L})$ and $\mathrm{Pd}(\mathrm{OH})_{2}(81 \mathrm{mg})$ were added to the stirred mixture, sequentially. It was then sealed with septa and parafilm. The glassware was evacuated with syringe, followed by charging with hydrogen gas provided by a balloon. Repeating the procedure twice, a mixed solution of $\mathrm{MeOH} / \mathrm{CHCl}_{3}(1 \mathrm{~mL}, 4 / 1)$ was added to compensate for the solvent reduced by evaporation. The mixture was then stirred under an atmosphere of a balloon filling with hydrogen for $23 \mathrm{~h}$. TLC $\left(\mathrm{NH}_{3} / \mathrm{MeOH} / \mathrm{CHCl}_{3}=1 / 5 / 5\right)$ indicated the consumption of the starting material $14 \beta\left(\mathrm{R}_{f}=0.95\right)$ and the formation of the product $17 \beta\left(\mathrm{R}_{f}=0.14\right)$. The mixture was then filtered through a Celite pad, followed by washing with $\mathrm{CHCl}_{3}$ and $\mathrm{MeOH}$, sequentially. The filtrates were combined and concentrated under reduced pressure to provide an off-white solid which was followed by washing with $\mathrm{CHCl}_{3}$ to remove some colored impurities. The wet solid was filtered and collected. The residue was dried under reduced pressure to afford a white solid in $86 \%$ yield $(16 \mathrm{mg})$. Recrystallization of a sample from water was unsuccessful. Instead, after concentration under reduced pressure, the solid become pale yellow. ${ }^{1} \mathrm{H}-\mathrm{NMR}\left(\mathrm{D}_{2} \mathrm{O}\right): \delta 0.82(\mathrm{bs}, 3 \mathrm{H}$, $\mathrm{CH}_{3}$ ), 1.23 (bs, 22H, $\mathrm{CH}_{2}$ ), 1.47 (bs, 1H), 1.72 (bs, 1H), 3.28 (bs, 2H), 3.54 (bs, 2H), 3.69 (bs, 2H), $3.81(\mathrm{bs}, 1 \mathrm{H}), 3.93(\mathrm{bs}, 2 \mathrm{H}), 4.05(\mathrm{bs}, 1 \mathrm{H}), 4.13(\mathrm{bs}, 1 \mathrm{H}), 4.50(\mathrm{bs}, 1 \mathrm{H}) ;{ }^{13} \mathrm{C}-\mathrm{NMR}\left(125 \mathrm{MHz}, \mathrm{D}_{2} \mathrm{O}\right): \delta$ $14.10\left(\mathrm{CH}_{3}\right), \mathrm{CH}_{2}: 22.86,25.51,29.74,30.21,32.21,34.02,40.46 ; 53.45(\mathrm{CH}), 65.56\left(\mathrm{CH}_{2}\right), 69.29$ $(\mathrm{CH}), 70.65(\mathrm{CH}), 71.04(\mathrm{CH}), 71.97(\mathrm{CH}), 72.20(\mathrm{CH}), 72.39(\mathrm{CH}), 102.48(\mathrm{CH})$; LRMS for $\mathrm{C}_{23} \mathrm{H}_{48} \mathrm{~N}_{2} \mathrm{O}_{7}: \mathrm{MW}=464.6, \mathrm{M}$ (calcd.) $=464.4(\mathrm{~m} / z), \mathrm{ESI}+\mathrm{Q}-\mathrm{TOF}: \mathrm{M}=464.4(\mathrm{~m} / \mathrm{z}),[\mathrm{M}+\mathrm{H}]^{+}=465.4$ (13.4\%), 466.4 (4.2\%), approximately equivalent to the calculated isotopic ratio (100\%:25.1\%).

2-Amino-1-O-(6-amino- $\alpha$-D-galactopyranosyl)-D-ribo-octadecan-3,4-diol (2): To a mixture of starting material $15 \alpha$ and $\mathrm{MeOH}(8 \mathrm{~mL})$ was added $\mathrm{NaOMe}(3 \mathrm{mg}, 0.05 \mathrm{mmol}, 0.5$ eq.). The stirring was allowed for $1 \mathrm{~h}$. TLC (EtOAc/n-hexane $=1: 4$ ) indicated the consumption of the starting material $\mathbf{1 5} \boldsymbol{\alpha}$ $\left(\mathrm{R}_{f}=0.90\right)$ and the formation of the product $\left(\mathrm{R}_{f}=0.58\right)$. After adding the cationic exchange resin $(\mathrm{H}+)$, 
the $\mathrm{pH}$ was adjusted to neutral. The mixture was filtered through a Celite pad. The filtrate was concentrated and the residue obtained was further purified using column chromatography $\left(\mathrm{MeOH} / \mathrm{CHCl}_{3}\right.$ 1:9) to afford white solid of 2-azido-1-O-(6-azido-2,3,4-tri-O-benzyl- $\alpha-D-$ galactopyranosyl)-D-ribo-octadecan-3,4-diol in 90\% yield (57 mg). ${ }^{1} \mathrm{H}-\mathrm{NMR}\left(\mathrm{CD}_{3} \mathrm{OD}\right): \delta 0.88(\mathrm{t}, 3 \mathrm{H}$, $\left.J=7.0 \mathrm{~Hz}, \mathrm{H}_{\text {aliphatic }}\right), 1.26-1.36\left(\mathrm{~m}, 24 \mathrm{H}, \mathrm{H}_{\text {aliphatic }}\right), 1.60-1.80$ (m, 2H, $\left.\mathrm{H}_{\text {aliphatic }}\right), 3.14$ (dd, $1 \mathrm{H}$, $\left.J_{6 \mathrm{a}^{\prime}, 6 \mathrm{~b}^{\prime}}=12.5 \mathrm{~Hz}, J_{6 \mathrm{a}^{\prime}, 5^{\prime}}=4.5 \mathrm{~Hz}, \mathrm{H}_{6 \mathrm{a}^{\prime}}\right), 3.48\left(\mathrm{dd}, J_{6 \mathrm{~b}^{\prime}, 6 \mathrm{a}^{\prime}}=12.5 \mathrm{~Hz}, J_{6 \mathrm{~b}^{\prime}, 5^{\prime}}=8.5 \mathrm{~Hz}, 1 \mathrm{H}, \mathrm{H}_{6 \mathrm{~b}^{\prime}}\right), 3.52-3.57$ (m, $1 \mathrm{H}), 3.59$ (dd, $J=7.0,4.5 \mathrm{~Hz}, 1 \mathrm{H}), 3.70-3.73$ (m, 1H), 3.75 (dd, $J=10.5,6.5 \mathrm{~Hz}, 1 \mathrm{H}), 3.94$ (bs, $1 \mathrm{H})$, $3.96(\mathrm{dd}, J=10.0,2.5 \mathrm{~Hz}, 1 \mathrm{H}), 4.00(\mathrm{dd}, J=10.0,3.5 \mathrm{~Hz}, 1 \mathrm{H}), 4.10(\mathrm{dd}, J=10.0,2.5 \mathrm{~Hz}, 1 \mathrm{H}), 4.55$ $\left(\mathrm{d}, J=11.5 \mathrm{~Hz}, 1 \mathrm{H}, \mathrm{C}_{2} \mathrm{Ph}\right), 4.73-4.77\left(\mathrm{~m}, 4 \mathrm{H}, \underline{\mathrm{C}}_{2} \mathrm{Ph}\right), 4.90\left(\mathrm{~d}, J=11.0 \mathrm{~Hz}, 1 \mathrm{H}, \mathrm{C}_{2} \mathrm{Ph}\right), 4.94(\mathrm{~d}, 1 \mathrm{H}$, $\left.J_{1,2}=3.5 \mathrm{~Hz}, \mathrm{H}_{1}\right), 7.26-7.38$ (m, 15H, $\left.\mathrm{ArH}\right) ;{ }^{13} \mathrm{C}-\mathrm{NMR}\left(\mathrm{CD}_{3} \mathrm{OD}\right): \delta 14.46\left(\mathrm{CH}_{3}\right), \mathrm{CH}_{2}: 23.74,26.74$, 30.48, 30.76, 30.79, 33.07, 34.14, 52.61; $63.68(\mathrm{CH}), 68.98\left(\mathrm{CH}_{2}\right), 71.66(\mathrm{CH}), 73.01(\mathrm{CH}), 74.18$ $\left(\mathrm{CH}_{2}, \underline{\mathrm{CH}}_{2} \mathrm{Ph}\right), 74.28\left(\mathrm{CH}_{2}, \underline{\mathrm{CH}_{2}} \mathrm{Ph}\right), 75.99\left(\mathrm{CH}_{2}, \underline{\mathrm{CH}}_{2} \mathrm{Ph}\right), 76.46(\mathrm{CH}), 76.96(\mathrm{CH}), 77.30(\mathrm{CH})$, 79.85(CH), 99.68( CH), arom. CH: 128.68, 128.79, 128.89, 129.17, 129.33, 129.36, 129.39, 129.42; arom. quaternary $\mathrm{C}$ : 139.70, 139.80, 139.96; LRMS for $\mathrm{C}_{45} \mathrm{H}_{64} \mathrm{~N}_{6} \mathrm{O}_{7}: \mathrm{M}$ (calcd.) $=800.5(\mathrm{~m} / \mathrm{z})$, ESI+Q-TOF: $\mathrm{M}=800.3(\mathrm{~m} / \mathrm{z}),[\mathrm{M}+\mathrm{Na}]^{+}=823.3$. The similar procedure as described for compound 17 was employed. The benzoyl-group-removed compound (57 $\mathrm{mg}, 0.07 \mathrm{mmol}$ ), a cosolvent of $\mathrm{MeOH}(8 \mathrm{~mL})$ and $\mathrm{CHCl}_{3}(2 \mathrm{~mL})$, glacial $\mathrm{AcOH}(30 \mu \mathrm{L})$ and $\mathrm{Pd}(\mathrm{OH})_{2}(114 \mathrm{mg})$ were employed. TLC $\left(\mathrm{NH}_{3} / \mathrm{MeOH} / \mathrm{CHCl}_{3}=0.2 / 1 / 1\right)$ indicated the formation of the product $\left(\mathrm{R}_{f}=0.13\right)$ and the consumption of the starting material $\left(\mathrm{R}_{f}=0.95\right)$. After $30 \mathrm{~h}$, the mixture was filtered through a Celite pad and washed with $\mathrm{MeOH}$ to obtain the filtrate. After concentration under reduced pressure, a white solid of product 2 was obtained in $90 \%$ yield $\left(30 \mathrm{mg}\right.$ ). LRMS for $\mathrm{C}_{24} \mathrm{H}_{50} \mathrm{~N}_{2} \mathrm{O}_{7}$ : $\mathrm{M}$ (calcd.) $=478.4(\mathrm{~m} / z)$, ESI+Q-TOF: $\mathrm{M}=478.36(\mathrm{~m} / \mathrm{z}),[\mathrm{M}+\mathrm{H}]^{+}=479.3(94.0 \%), 480.3(28.9 \%), 481.3(5.8 \%)$, approximately equivalent to the calculated isotopic ratio (100\%:26.8\%:4.9\%).

$\mathrm{N}$-((2S,3S,4R)-2-Amino-3,4-dihydroxyheptadecyl)-4-butylbenzamide (18): Compound 1 (15 mg, $0.05 \mathrm{mmol}$ ), 4-butylbenzoic acid (1 eq.) and HBTU (1.2 eq.) were used, respectively. Purification used column chromatography with eluents of $\mathrm{MeOH} / \mathrm{CHCl}_{3}$ 1:19 $\rightarrow 1: 12$ to afford product mixtures, which were observed to be pure in TLC. Further purification using HPLC as described above but with $\mathrm{MeOH} / \mathrm{CHCl}_{3}$ 1:13 as eluent was used to collect the fraction under the area between 8.5 and $10.5 \mathrm{~min}$. Product 18 was obtained in $35 \%$ yield $(8 \mathrm{mg})$. Reinjection of the concentrated fraction into HPLC showed two peaks in the chromatogram. These were suspected to be two conformers due to rotation. Miscellaneuous small unidentified peaks in ${ }^{1} \mathrm{H}-\mathrm{NMR}$ were impurities, which were also observable in the HPLC chromatogram. The impurities were suspected to be the unremoved diisopropylethylamine, which was confirmed from the spectrum of ESI-MS: $[\mathrm{M}+\mathrm{H}]^{+}=130.2(28 \%), 131.2(3 \%)$; ${ }^{1} \mathrm{H}-\mathrm{NMR}$ $\left(\mathrm{C}_{6} \mathrm{D}_{6}\right): \delta$ 0.90-0.96 (m, 6H, Haliphatic), 1.25-1.50 (m, 22H, $\left.\mathrm{H}_{\text {aliphatic }}\right), 1.62-1.80\left(\mathrm{~m}, 4 \mathrm{H}, \mathrm{H}_{\text {aliphatic }}\right)$, 2.02-2.12 (m, 2H), 2.44-2.47 (m, 2H), 3.99-4.24 (m, 5H), 7.13-7.15 (m, 2H, ArH), 8.04-8.06 (m, 2H, $\mathrm{ArH}), 8.29$ (bs, $1 \mathrm{H}$, amide); ${ }^{13} \mathrm{C}-\mathrm{NMR}\left(\mathrm{C}_{6} \mathrm{D}_{6}\right): \delta 8.13,14.10,14.37,22.78,23.14,26.36,29.92,30.27$, $30.38,30.45,30.49,30.53,32.39,33.45,35.83$, 46.62, 54.92, 66.20, 72.60, 74.10, 127.47, 129.01, 130.67, 147.83, 170.38; LRMS for $\mathrm{C}_{28} \mathrm{H}_{50} \mathrm{~N}_{2} \mathrm{O}_{3}$ : M (calcd.) $=462.4(\mathrm{~m} / \mathrm{z})$, ESI+Q-TOF: $\mathrm{M}=462.4$ $(\mathrm{m} / \mathrm{z}),[\mathrm{M}+\mathrm{H}]^{+}=463.4(100 \%), 464.4(29 \%), 465.4(5 \%),[\mathrm{M}+\mathrm{Na}]^{+}=485.3(8 \%), 486.4(2 \%)$, approximately equivalent to the calculated isotopic ratio (100\%:31\%:5.3\%). 
4-Butyl-N-(((2R,3R, 4S, 5R, 6S)-6-(((2S,3S,4R)-2-(4-butylbenzamido)-3,4-dihydroxyoctadecyl)oxy)3,4,5-trihydroxytetrahydro-2H-pyran-2-yl)methyl)benzamide (19): To a mixture of 4-butylbenzoic acid (23 mg, $0.13 \mathrm{mmol}, 2.1$ equiv), HBTU (57 mg, $0.15 \mathrm{mmol}, 2.4$ equiv) and DMF (6 mL) was added diisopropylethylamine (14 $\mu \mathrm{L}, 0.08 \mathrm{mmol}, 1.3$ eq.) under $\mathrm{N}_{2}$. After stirring for $10 \mathrm{~min}$, TLC (EtOAc/ $n$-hexane $=1: 3)$ indicated the formation of the ester intermediate $\left(\mathrm{R}_{f}=0.73\right)$ and consumption of the starting 4-butylbenzoic acid $\left(\mathrm{R}_{f}=0.12\right)$. To this mixture was added the solution of compound 2 (30 $\mathrm{mg}$, $0.06 \mathrm{mmol})$ in DMF (4 mL). After stirring for $30 \mathrm{~h}$, TLC $\left(\mathrm{NH}_{3} / \mathrm{MeOH} / \mathrm{CHCl}_{3}=0.2: 1: 1\right)$ indicated the formation of the product $19\left(\mathrm{R}_{f}=0.89\right)$ and consumption of the starting compound $2\left(\mathrm{R}_{f}=0.14\right)$. The mixture was concentrated under reduced pressure. The residue obtained was purified using column chromatography (EtOAc/ $n$-hexane $=1: 4)$ to afford 19 as a white solid in $60 \%$ yield $(31 \mathrm{mg})$. The sample was further purified using HPLC $\left(0.9 \mathrm{~cm} \times 20 \mathrm{~cm}\right.$, Si-100) with $\mathrm{MeOH} / \mathrm{CHCl}_{3}=1: 29$ as eluent at a flow rate of $3 \mathrm{~mL} / \mathrm{min}$ to a afford white solid $(5 \mathrm{mg}) ; t_{R}=19.2 \mathrm{~min} ; t_{R}=11.9 \mathrm{~min}$ (aromatic impurities). Anal. $\mathrm{C}_{46} \mathrm{H}_{74} \mathrm{~N}_{2} \mathrm{O}_{9}, \mathrm{M}$ (calcd.) = $798.5(\mathrm{~m} / \mathrm{z})$, ESI+Q-TOF: $\mathrm{M}=798.6(\mathrm{~m} / \mathrm{z}),[\mathrm{M}+\mathrm{H}]^{+}=799.6(19.04 \%)$, $800.6(10.99 \%),[\mathrm{M}+\mathrm{Na}]^{+}=821.6(100 \%), 822.6(50.09 \%), 823.6(11.33 \%)$, equivalent to the calculated isotopic ratio 100:50.8:12.7; HRMS (ESI) M (calcd.) = $798.53943(\mathrm{~m} / \mathrm{z}), \mathrm{M}$ (found) $=798.53975(\mathrm{~m} / \mathrm{z})$; ${ }^{1} \mathrm{H}-\mathrm{NMR}\left(\mathrm{CD}_{3} \mathrm{OD}\right): \delta 0.87-0.94\left(\mathrm{~m}, 9 \mathrm{H}, \mathrm{H}_{\text {aliphatic }}\right), 1.21-1.40\left(\mathrm{~m}, 28 \mathrm{H}, \mathrm{H}_{\text {aliphatic }}\right), 1.60-1.70(\mathrm{~m}, 5 \mathrm{H}$, $\left.\mathrm{H}_{\text {aliphatic }}\right), 2.61-2.67(\mathrm{~m}, 4 \mathrm{H}), 3.44-3.48(\mathrm{~m}, 1 \mathrm{H}), 3.56-3.60(\mathrm{~m}, 1 \mathrm{H}), 3.67-3.82(\mathrm{~m}, 6 \mathrm{H}), 3.93-4.00$ $(\mathrm{m}, 2 \mathrm{H}), 4.40-4.44(\mathrm{dd}, 1 \mathrm{H}, J=10.5, J=5.0 \mathrm{~Hz}), 4.93-4.94\left(\mathrm{~d}, 1 \mathrm{H}, J=3.5 \mathrm{~Hz}, \mathrm{H}_{1}\right), 7.20-7.25$ (m, $4 \mathrm{H}, \mathrm{ArH}), 7.67-7.71(\mathrm{~m}, 4 \mathrm{H}, \mathrm{ArH}) ;{ }^{13} \mathrm{C}-\mathrm{NMR}\left(\mathrm{CD}_{3} \mathrm{OD}\right): \delta 14.18\left(\mathrm{CH}_{3}\right), 14.36\left(\mathrm{CH}_{3}\right), 23.29\left(\mathrm{CH}_{2}\right)$, $23.32\left(\mathrm{CH}_{2}\right), 23.67\left(\mathrm{CH}_{2}\right), 26.77\left(\mathrm{CH}_{2}\right), 30.41\left(\mathrm{CH}_{2}\right), 30.71\left(\mathrm{CH}_{2}\right), 30.75\left(\mathrm{CH}_{2}\right), 33.03\left(\mathrm{CH}_{2}\right), 33.47$ $\left(\mathrm{CH}_{2}\right), 34.54\left(\mathrm{CH}_{2}\right), 36.46\left(\mathrm{CH}_{2}\right), 41.69\left(\mathrm{CH}_{2}\right), 52.60\left(\mathrm{CH}_{2}\right), 67.96\left(\mathrm{CH}_{2}\right), 70.18(\mathrm{CH}), 70.52(\mathrm{CH})$, $71.29(\mathrm{CH}), 71.46(\mathrm{CH}), 73.04(\mathrm{CH}), 75.85\left(\mathrm{CH}_{3}\right), 101.13(\mathrm{CH})$, arom: 128.38, 128.46, 129.57, 132.93, 133.19, 148.34, 148.27; 169.93 (amide), 170.76 (amide).

\subsection{Preparation of Cell Lines and MTT Assay}

\subsubsection{Cell Culture}

Adherent normal human fibroblast and U87 cells were maintained at $37{ }^{\circ} \mathrm{C}$ in a humidified $\mathrm{CO}_{2}$-controlled atmosphere in Minimum Essential Medium (MEM) (Sigma-Aldrich) supplemented with 10\% heat-inactivated fetal bovine serum (FBS) (Biological Industries). In addition, adherent A549 and $\mathrm{C} 26$ cells were maintained at $37{ }^{\circ} \mathrm{C}$ in a humidified $\mathrm{CO}_{2}$-controlled atmosphere in RPMI 1640 (Sigma-Aldrich) supplemented with 10\% heat-inactivated fetal bovine serum (FBS) (Biological Industries).

\subsubsection{MTT Assay of Amide-Bond Formation Products}

\subsubsection{Cell Plating}

Briefly, 3,000 cells per well were plated in 96-well microtiter plates with $100 \mu \mathrm{L}$ MEM/10\%FBS and incubated at $37^{\circ} \mathrm{C}$ in a humidified $\mathrm{CO}_{2}$-controlled atmosphere for 1 day. 


\subsubsection{Construction of Amide Bonding Libraries and Their Cytotoxicity Screening}

We used 44 carboxylic acids (Figure 2) to construct amide bonding libraries. Every carboxylic acid (1 eq., dissolved in $25 \mu \mathrm{L}$ DMSO) was activated by HBTU (1.1 eq., $4.1 \mathrm{mg}$, dissolved in $23 \mu \mathrm{L}$ DMSO) and DIEA (1.2 eq., $0.012 \mathrm{mmol}, 2 \mu \mathrm{L})$. The amide bonding reaction was carried out by coupling a portion of crude active ester $(10 \mu \mathrm{L}, 0.2 \mathrm{M}$, dissolved in DMSO) with amine (10 $\mu \mathrm{L}, 0.2 \mathrm{M}$, dissolved in DMSO). After completion of amide bond formation, a portion of the crude product $(0.1 \mathrm{M}$, dissolved in $4 \mu \mathrm{L}$ DMSO) was diluted by de-ionized sterilized water $(396 \mu \mathrm{L})$ and filtrated with $0.2 \mu \mathrm{m}$ filter. The filtrate ( $1 \mathrm{mM}$ crude product in $10 \mu \mathrm{L}$ water containing $1 \%(\mathrm{v} / \mathrm{v}) \mathrm{DMSO}$ ) was diluted with $100 \mu \mathrm{L}$ culture medium in the previous cell-plated microtiter plates so that the concentration of DMSO was less than $0.1 \%(\mathrm{v} / \mathrm{v})$, and the crude product was less than $100 \mu \tilde{\mathrm{M}}$ These microtiter plates was further incubated at $37{ }^{\circ} \mathrm{C}$ in a humidified $\mathrm{CO}_{2}$-controlled atmosphere for 2 days. 3-(4,5-dimethylthiazol-2-yl)-2,5-diphenyltetrazolium bromide ( $0.5 \mathrm{mg}$ dissolved in $1 \mathrm{~mL}$ PBS buffer) was added to previous microtiter plates and incubated for $4 \mathrm{~h}$. After removing the culture medium from microtiter plates and dissolving insoluble formazan with $100 \mu \mathrm{L}$ DMSO, cytotoxicity screening data was obtained by dectecting the absorbance of $570 \mathrm{~nm}$ with microtiter plate reader (Plate CHAMELEON $^{\mathrm{TM}}$ ). The MTT assay results are shown below (Figure 4).

Figure 4. Analog 18 (A11) showed the less cytotoxicites against normal human fibroblasts (50\% in U87 cells). A40 was obtained from (2R,3R)-2,3-bis(4-methylbenzoyloxy)succinic acid. Purification of the product mixtures of A40 with HPLC generated a number of unidentified peaks in chromatogram.

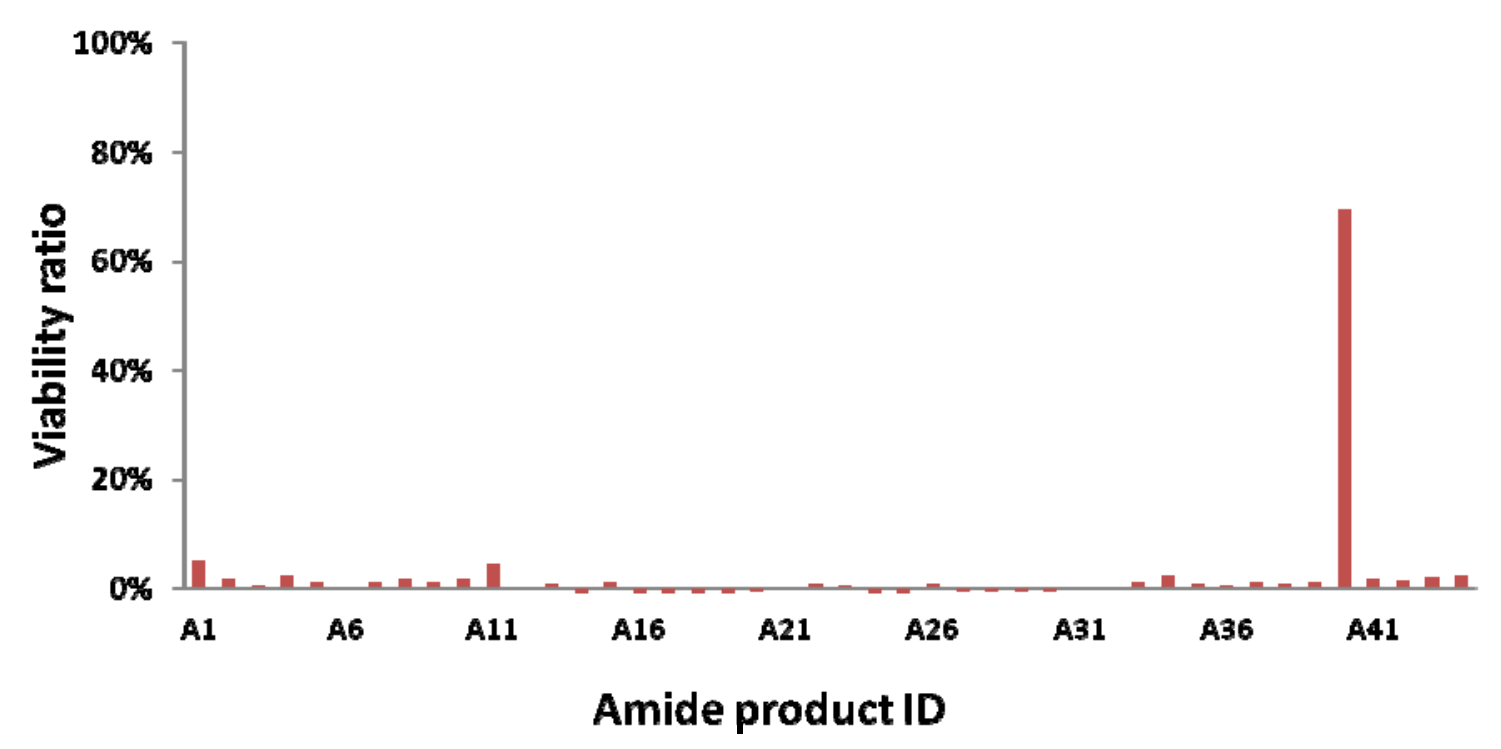

\subsection{Invariant Nature Killer Cell Quantification}

The iNKT was obtained from peripheral blood monocytes (PBMC) of healthy donors after gradientseparated at 400 g, 30 min with Ficoll-Hypaque ${ }^{\mathrm{TM}}$ plus (GE Healthcare, CA, USA). The cells were cultured and enriched in RPMI with L-glutamin (Gibco, NY, USA) with supplement of 10\% fetal calf serum and $1 \%$ penicillin-streptomycin. $\alpha$-Galactosylceramide ( $\alpha$-GalCer, Kirin, Gunma, Japan) was 
added to the medium at defined concentration every 3 days. The iNKT population was either identified or sorted (fluorescence-activated cell sorted (FACS), magnetic cell seperation) with antibodies against $\mathrm{V} \alpha 24^{+} / \mathrm{V} \beta 11^{+}$. The antibodies for staining T-cell receptors (TCR, $\mathrm{V} \alpha 24^{+} / \mathrm{V} \beta 11^{+}$) were purchased from Beckman Coulter (city?CA, USA), BD bioscience (NJ, USA) and Miltenyi-Biotec (CA, USA). Briefly, after 7-10 days of incubation, the cultured cells were analyzed with flow cytometry.

\section{Conclusions}

The 6-aminogalactosylsphingosine analog has been prepared as core compound for the construction of libraries. A mini library comprising $40+$ compounds have been generated through parallel solution phase synthesis via amide bond formation. A preliminary test of the bioactivity including the use of cytotoxicity assays and flow cytometry assays for NKT cell proliferation have been performed accordingly. A subtle inducement of the subpopulation of V 24+/V- $\beta 11+$ cells by compound 19 needs further study to clarify its role.

\section{Supplementary Materials}

Supplementary materials can be accessed at: http://www.mdpi.com/1420-3049/17/3/3058/s1.

\section{Acknowledgments}

We are grateful to National Science Council of Taiwan and CGMH_NTHU Joint Research for providing financial support (NSC-98-2113-M-007-012 and CMRPG390111 and CGTH96N2342E1).

\section{Conflict of Interest}

The authors declare no conflict of interest.

\section{References and Notes}

1. Morita, M.; Motoki, K.; Akimoto, K.; Natori, T.; Sakai, T.; Sawa, E.; Yamaji, K.; Koezuka, Y.; Kobayashi, E.; Fukushima, H. Structure-activity relationship of alpha-galactosylceramides against B16-bearing mice. J. Med. Chem. 1995, 38, 2176-2187.

2. Natori, T.; Morita, M.; Akimoto, K.; Koezuka, Y. Agelasphins, novel antitumor and immunostimulatory cerebrosides from the marine sponge Agelas mauritianus. Tetrahedron 1994, 50, 2771-2784.

3. Singh, R.; Sharma, M.; Joshi, P.; Rawat, D.S. Clinical status of anti-cancer agents derived from marine sources. Anti-Cancer Agents Med. Chem. 2008, 8, 603-610.

4. Padron, J.M. Sphingolipids in anticancer therapy. Curr. Med. Chem. 2006, 13, 755-770.

5. Godfrey, D.I.; Kronenberg, M. Going both ways: Immune regulation via CD1d-dependent NKT cells. J. Clin. Invest. 2004, 114, 1379-1388.

6. Kawano, T.; Cui, J.Q.; Koezuka, Y.; Toura, I.; Kaneko, Y.; Motoki, K.; Ueno, H.; Nakagawa, R.; Sato, H.; Kondo, E.; et al. CD1d-restricted and TCR-mediated activation of V(alpha)14 NKT cells by glycosylceramides. Science 1997, 278, 1626-1629. 
7. Zajonc, D.M.; Cantu, C.; Mattner, J.; Zhou, D.P.; Savage, P.B.; Bendelac, A.; Wilson, I.A.; Teyton, L. Structure and function of a potent agonist for the semi-invariant natural killer $\mathrm{T}$ cell receptor. Nat. Immunol. 2005, 6, 810-818.

8. Kulkarni, S.S.; Gervay-Hague, J. Chemical Glycobiology I: Glycoconjugates and CarbohydrateProtein Interactions; ACS Symposium Series 990; American Chemical Society: Washington, DC, USA, 2008; pp. 153-166.

9. Wu, D.; Fujio, M.; Wong, C.-H. Glycolipids as immunostimulating agents. Bioorg. Med. Chem. 2008, 16, 1073-1083.

10. Kinjo, Y.; Wu, D.; Kim, G.S.; Xing, G.W.; Poles, M.A.; Ho, D.D.; Tsuji, M.; Kawahara, K.; Wong, C.H.; Kronenberg, M. Recognition of bacterial glycosphingolipids by natural killer T cells. Nature 2005, 4341, 520-525.

11. Wu, D.; Xing, G.W.; Poles, M.A.; Horowitz, A.; Kinjo, Y.; Sullivan, B.; Bodmer-Narkevitch, V.; Plettenburg, O.; Kronenberg, M.; Tsuji, M.; et al. Bacterial glycolipids and analogs as antigens for CD1d-restricted NKT cells. Proc. Natl. Acad. Sci. USA 2005, 102, 1351-1356.

12. Fujio, M.; Wu, D.G.; Garcia-Navarro, R.; Ho, D.D.; Tsuji, M.; Wong, C.H. Structure-based discovery of glycolipids for CD1d-mediated NKT cell activation: Tuning the adjuvant versus immunosuppression activity. J. Am. Chem. Soc. 2006, 128, 9022-9023.

13. Gonzalez-Aseguinolaza, G.; Van Kaer, L.; Bergmann, C.C.; Wilson, J.M.; Schmieg, J.; Kronenberg, M.; Nakayama, K.; Taniguchi, M.; Koezuka, Y.; Tsuji, M. Natural killer T cell ligand alpha-galactosylceramide enhances protective immunity induced by malaria vaccines. J. Exp. Med. 2002, 195, 617-624.

14. Savage, P.B.; Teyton, L.; Bendelac, A. Glycolipids for natural killer T cells. Chem. Soc. Rev. 2006, 35, 771-779.

15. Giaccone, G.; Punt, C.J.A.; Ando, Y.; Ruijter, R.; Nishi, N.; Peters, M.; von Blomberg, B.M.E.; Scheper, R.J.; van der Vliet, H.J.J.; van den Eertwegh, A.J.M.; et al. A phase I study of the natural killer T-cell ligand alpha-Galactosylceramide (KRN7000) in patients with solid tumors. Clin. Cancer Res. 2002, 8, 3702-3709.

16. Subleski, J.J.; Hall, V.L.; Wolfe, T.B.; Scarzello, A.J.; Weiss, J.M.; Chan, T.; Hodge, D.L.; Back, T.C.; Ortaldo, J.R.; Wiltrout, R.H. TCR-Dependent and -independent activation underlie liver-specific regulation of NKT cells. J. Immunol. 2011, 186, 838-847.

17. Lu, X.; Song, L.; Metelitsa, L.S.; Bittman, R. Synthesis and evaluation of an alpha-CGalactosylceramide analogue that induces Th1-biased responses in human natural killer T cells. ChemBioChem 2006, 7, 1750-1756.

18. Chen, W.L.; Xia, C.F.; Cai, L.; Wang, P.G. Efficient synthesis of galactosylceramide analogues for iNKT cell stimulation. Bioorg. Med. Chem. Lett. 2010, 20, 3859-3862.

19. Miyamoto, K.; Miyake, S.; Yamamura, T. A synthetic glycolipid prevents autoimmune encephalomyelitis by inducing T(H)2 bias of natural killer T cells. Nature 2001, 413, 531-534.

20. Li, Q.; Ndonye, R.M.; Illarionov, P.A.; Yu, K.O.A.; Jerud, E.S.; Diaz, K.; Bricard, G.; Porcelli, S.A.; Besra, G.S.; Chang, Y.T.; et al. Rapid identification of immunostimulatory alphagalactosylceramides using synthetic combinatorial libraries. J. Comb. Chem. 2007, 9, 1084-1093. 
21. Oki, S.; Tomi, C.; Yamamura, T.; Miyake, S. Preferential T(h)2 polarization by OCH is supported by incompetent NKT cell induction of CD40L and following production of inflammatory cytokines by bystander cells in vivo. Int. Immunol. 2005, 17, 1619-1629.

22. Yu, K.O.A.; Im, J.S.; Molano, A.; Cutronc, Y.; Illarinov, P.A.; Forestier, C.; Fujiwara, N.; Arias, I.; Miyake, S.; Yamamura, T.; et al. Modulation of CD1d-restricted NKT cell responses by using $\mathrm{N}$-acyl variants of alpha-galactosylceram ides. Proc. Natl. Acad. Sci. USA 2005, 102, 3383-3388.

23. Im, J.S.; Arora, P.; Bricard, G.; Molano, A.; Venkataswamy, M.M.; Baine, I.; Jerud, E.S.; Goldberg, M.F.; Baena, A.; Yu, K.O.A.; et al. Kinetics and cellular site of glycolipid loading control the outcome of natural killer T cell activation. Immunity 2009, 30, 888-898.

24. Yang, G.L.; Schmieg, J.; Tsuji, M.; Franck, R.W. The C-glycoside analogue of the immunostimulant alpha-galactosylceramide (KRN7000): Synthesis and striking enhancement of activity. Angew. Chem. Int. Ed. 2004, 43, 3818-3822.

25. Goff, R.D.; Gao, Y.; Mattner, J.; Zhou, D.P.; Yin, N.; Cantu, C.; Teyton, L.; Bendelac, A.; Savage, P.B. Effects of lipid chain lengths in alpha-galactosylceramides on cytokine release by natural killer T cells. J. Am. Chem. Soc. 2004, 126, 13602-13603.

26. Trappeniers, M.; Van Beneden, K.; Decruy, T.; Hillaert, U.; Linclau, B.; Elewaut, D.; Van Calenbergh, S. 6'-Derivatised alpha-GalCer analogues capable of inducing strong CD1dmediated Th1-biased NKT cell responses in mice. J. Am. Chem. Soc. 2008, 130, 16468-16469.

27. Koch, M.; Stronge, V.S.; Shepherd, D.; Gadola, S.D.; Mathew, B.; Ritter, G.; Fersht, A.R.; Besra, G.S.; Schmidt, R.R.; Jones, E.Y.; et al. The crystal structure of human CD1d with and without alpha-galactosylceramide. Nat. Immunol. 2005, 6, 819-826.

28. Borg, N.A.; Wun, K.S.; Kjer-Nielsen, L.; Wilce, M.C.J.; Pellicci, D.G.; Koh, R.; Besra, G.S.; Bharadwaj, M.; Godfrey, D.I.; McCluskey, J.; et al. CD1d-lipid-antigen recognition by the semi-invariant NKT T-cell receptor. Nature 2007, 448, 44-49.

29. Liu, Y.; Goff, R.D.; Zhou, D.P.; Mattner, J.; Sullivan, B.A.; Khurana, A.; Cantu, C.; Ravkov, E.V.; Lbegbu, C.C.; Altman, J.D.; et al. A modified alpha-galactosyl ceramide for staining and stimulating natural killer T cells. J. Immunol. Methods 2006, 312, 34-39.

30. Xia, C.F.; Zhang, W.P.; Zhang, Y.L.; Woodward, R.L.; Wang, J.H.; Wang, P.G. Facile synthesis of biotin-labelled alpha-galactosylceramide as antigen for invariant natural killer $\mathrm{T}$ cells. Tetrahedron 2009, 65, 6390-6395.

31. Liu, Y.; Goff, R.D.; Zhou, D.P.; Mattner, J.; Sullivan, B.A.; Khurana, A.; Cantu, C.; Ravkov, E.V.; Lbegbu, C.C.; Altman, J.D.; et al. Synthesis and NKT cell stimulating properties of fluorophore- and biotin-appended 6"-amino-6"-deoxy-galactosylceramides. Org. Lett. 2002, 4, 1267-1270.

32. Prigozy, T.I.; Naidenko, O.; Qasba, P.; Elewaut, D.; Brossay, L.; Khurana, A.; Natori, T.; Koezuka, Y.; Kulkarni, A.; Kronenberg, M. Glycolipid antigen processing for presentation by CD1d molecules. Science 2001, 291, 664-667.

33. Jervis, P.J.; Cox, L.R.; Besra, G.S. Synthesis of a versatile building block for the preparation of 6- $N$-derivatized alpha-galactosyl ceramides: Rapid access to biologically active glycolipids. J. Org. Chem. 2011, 76, 320-323.

34. Schombs, M.; Park, F.E.; Du, W.J.; Kulkarni, S.S.; Gervay-Hague, J. One-pot syntheses of immunostimulatory glyeolipids. J. Org. Chem. 2010, 75, 4891-4898. 
35. Du, W.J.; Gervay-Hague, J. Efficient synthesis of alpha-galactosyl ceramide analogues using glycosyl iodide donors. Org. Lett. 2005, 7, 2063-2065.

36. Du, W.; Kulkarni, S.S.; Gervay-Hague, J. Efficient, one-pot syntheses of biologically active alpha-linked glycolipids. Chem. Commun. 2007, 23, 2336-2338.

37. Xing, G.W.; Wu, D.; Poles, M.A.; Horowitz, A.; Tsuji, M.; Ho, D.D.; Wong, C.H. Synthesis and human NKT cell stimulating properties of 3-O-sulfo-alpha/beta-galactosylceramides. Bioorg. Med. Chem. 2005, 13, 2907-2916.

38. Schmidt, R.R.; Zimmermann, P. Glycosylimidates. 23. synthesis of glycosphingolipids and psychosines. Angew. Chem. Int. Ed. Engl. 1986, 25, 725-726.

39. Chiang, L.W.; Pei, K.; Chen, S.W.; Huang, H.L.; Lin, K.J.; Yen, T.C.; Yu, C.S. Combining a solution-phase derived library with in-situ cellular bioassay: Prompt screening of amide-forming minilibraries using mtt assay. Chem. Pharm. Bull. 2009, 57, 714-718.

40. Su, Y.H.; Chiang, L.W.; Jeng, K.C.; Huang, H.L.; Chen, J.T.; Lin, W.J.; Huang, C.W.; Yu, C.S. Solution-phase parallel synthesis and screening of anti-tumor activities from fenbufen and ethacrynic acid libraries. Bioorg. Med. Chem. Lett. 2011, 21, 1320-1324.

41. Zhang, L.; Sun, F.; Li, Y.X.; Sun, X.; Liu, X.M.; Huang, Y.S.; Zhang, L.H.; Ye, X.S.; Xiao, J. Rapid synthesis of iminosugar derivatives for cell-based in situ screening: Discovery of "Hit" compounds with anticancer activity. ChemMedChem 2007, 2, 1594-1597.

42. Lin, K.-I.; Yang, C.-H.; Huang, C.-W.; Jian, J.-Y.; Huang, Y.-C.; Yu, C.-S. Synthesis and structure-activity relationships of fenbufen amide analogs. Molecules 2010, 15, 8796-8803.

43. Su, W.-C. Preparation of 6-amino galactosyl sphingosine analogs and its elaboration to amide libraries. Master thesis, National Tsing-Hua University, Hsinchu, Taiwan, 2010.

44. Chiang, L.-W.; Pan, S.-D.; Lo, J.-M.; Yu, C.-S. Triflic acid-promoted formylation of ceramide in dimethylformamide. Chin. J. Chem. 2009, 27, 2296-2299.

45. Garner, P.; Park, J.M. The synthesis and configurational stability of differentially protected betahydroxy-alpha-amino aldehydes. J. Org. Chem. 1987, 52, 2361-2364.

46. Alper, P.-B.; Hung, S.-C.; Wong, C.-H. Metal catalyzed diazo transfer for the synthesis of azides from amines. Tetrahedron Lett. 1996, 37, 6029-6032.

47. Kuroda, I.; Musman, M.; Ohtani, I.; Ichiba, T.; Tanaka, J.; Gravalos, D.G.; Higa, T. Pachastrissamine, a cytotoxic anhydrophytosphingosine from a marine sponge, Pachastrissa sp. J. Nat. Prod. 2002, 65, 1505-1506.

48. Noyce, D.S.; Virglio, J.A. Synthesis and solvolysis of 1-phenylethyl disubstituted phosphinates. J. Org. Chem. 1972, 37, 2643-2647.

49. Yu, C.-S.; Wang, R.-T.; Chiang, L.-W.; Lee, M.-H. Synthesis of 4',4'-C-diaminomethyl nucleoside derivative as a building block for constructing libraries via amide bond formation. Tetrahedron Lett. 2007, 48, 2979-2982.

50. Jagdhane, R.C.; Shashidhar, M.S. Orthogonally protected cyclohexanehexols by a "One Reaction-One Product" approach: Efficient access to cyclitols and their analogs. Eur. J. Org. Chem. 2010, 2945-2953.

51. Mitra, A.; DePue, L.J.; Struss, J.E.; Patel, B.P.; Parkin, S.; Atwood, D.A. Mononuclear Schiff base boron halides: Synthesis, characterization, and dealkylation of trimethyl phosphate. Inorg. Chem. 2006, 45, 9213-9224. 
52. Keizer, T.S.; DePue, L.J.; Parkin, S.; Atwood, D.A. Boron halide chelate compounds and their activity towards the demethylation of trimethylphosphate. Can. J. Chem. 2002, 80, 1463-1468.

53. Patel, A.; Lindhorst, T.K. Synthesis of "mixed type" oligosaccharide mimetics based on a carbohydrate scaffold. Eur. J. Org. Chem. 2002, 1, 79-86.

54. Plettenburg, O.; Bodmer-Narkevitch, V.; Wong, C.-H. Synthesis of alpha-galactosyl ceramide, a potent immunostimulatory agent. J. Org. Chem. 2002, 67, 4559-4564.

55. Hansen, H.C.; Magnusson, G. Synthesis of selected aminodeoxy analogues of galabiose and globotriose. Carbohydr. Res. 1999, 322, 166-180.

56. Greenberg, W.A.; Priestley, E.S.; Sears, P.S.; Alper, P.B.; Rosenbohm, C.; Hendrix, M.; Hung, S.C.; Wong, C.H. Design and synthesis of new aminoglycoside antibiotics containing neamine as an optimal core structure: Correlation of antibiotic activity with in vitro inhibition of translation. J. Am. Chem. Soc. 1999, 121, 6527-6541.

57. Mydock, L.K.; Demchenko, A.V. Superarming the S-benzoxazolyl glycosyl donors by simple 2-O-benzoyl-3,4,6-tri-O-benzyl protection. Org. Lett. 2008, 10, 2103-2106.

58. Morales-Serna, J.A.; Boutureira, O.; Diaz, Y.; Matheu, M.I.; Castillon, S. Recent advances in the glycosylation of sphingosines and ceramides. Carbohydr. Res. 2007, 342, 1595-1612.

59. Xia, C.F.; Yao, Q.J.; Schumann, J.; Rossy, E.; Chen, W.L.; Zhu, L.Z.; Zhang, W.P.; De Libero, G.; Wang, P.G. Synthesis and biological evaluation of alpha-galactosylceramide (KRN7000) and isoglobotrihexosylceramide (iGb3). Bioorg. Med. Chem. Lett. 2006, 16, 2195-2199.

60. Polt, R.; Szabo, L.; Treiberg, J.; Li, Y.; Hruby, V.J. General methods for alpha-o-ser/thr or beta-oser/thr glycosides and glycopeptides solid phase synthesis of o-glycosyl cyclic enkephalin analogs. J. Am. Chem. Soc. 1992, 114, 10249-10258.

61. Fan, G.T.; Pan, Y.S.; Lu, K.C.; Cheng, Y.P.; Lin, W.C.; Lin, S.; Lin, C.H.; Wong, C.H.; Fang, J.M.; Lin, C.C. Synthesis of alpha-galactosyl ceramide and the related glycolipids for evaluation of their activities on mouse splenocytes. Tetrahedron 2005, 61, 1855-1862.

Sample Availability: Contact the authors.

(C) 2012 by the authors; licensee MDPI, Basel, Switzerland. This article is an open access article distributed under the terms and conditions of the Creative Commons Attribution license (http://creativecommons.org/licenses/by/3.0/). 